\title{
Caprock integrity and public perception studies of carbon storage in depleted hydrocarbon reservoirs
}

\author{
Adriana Paluszny ${ }^{\mathrm{a}, *}$, Caroline C. Graham ${ }^{\mathrm{b}}$, Katherine A. Daniels ${ }^{\mathrm{b}}$, Vasiliki Tsaparli ${ }^{\mathrm{a}, \mathrm{e}}$, Dimitrios Xenias ${ }^{\mathrm{d}}$, Saeed \\ Salimzadeh $^{\mathrm{c}}$, Lorraine Whitmarsh ${ }^{\mathrm{d}}$, Jon F. Harrington ${ }^{\mathrm{b}}$, Robert W. Zimmerman ${ }^{\mathrm{a}}$ \\ ${ }^{a}$ Department of Earth Science and Engineering, Imperial College, London, United Kingdom \\ ${ }^{b}$ British Geological Survey, Keyworth, Nottingham, United Kingdom \\ ${ }^{c}$ Commonwealth Scientific and Industrial Research Organisation, Clayton, Australia \\ ${ }^{d}$ School of Psychology, Cardiff University, United Kingdom \\ e Ørsted, London UK
}

\begin{abstract}
Capture and subsurface storage of $\mathrm{CO}_{2}$ is widely viewed as being a necessary component of any strategy to minimise and control the continued increase in average global temperatures. Existing oil and gas reservoirs can be re-used for carbon storage, providing a substantial fraction of the vast amounts of subsurface storage space that will be required for the implementation of carbon storage at an industrial scale. Carbon capture and storage (CCS) in depleted reservoirs aims to ensure subsurface containment, both to satisfy safety considerations, and to provide confidence that the containment will continue over the necessary timescales. Other technical issues that need to be addressed include the risk of unintended subsurface events, such as induced seismicity. Minimisation of these risks is key to building confidence in CCS technology, both in relation to financing/liability, and the development and maintenance of public acceptance. These factors may be of particular importance with regard to CCS projects involving depleted hydrocarbon reservoirs, where the mechanical effects of production activities must also be considered. Given the importance of caprock behaviour in this context, several previously published geomechanical caprock studies of depleted hydrocarbon reservoirs are identified and reviewed, comprising experimental and numerical studies of fourteen CCS pilot sites in depleted hydrocarbon reservoirs, in seven countries (Algeria, Australia, Finland, France, Germany, Netherlands, Norway, UK). Particular emphasis is placed on the amount and types of data collected, the mathematical methods and codes used to conduct geomechanical analysis, and the relationship between geomechanical aspects and public perception. Sound geomechanical assessment, acting to help minimise operational and financial/liability risks, and the careful recognition of the impact of public perception are two key factors that can contribute to the development of a successful CCS project in a depleted hydrocarbon reservoir.
\end{abstract}

Keywords: carbon capture, fluid injection, geomechanics, depleted reservoirs, caprock integrity, leakage

\section{Introduction}

Despite attempts in Europe, the United States, and elsewhere to phase out the use of carbon-based energy sources, a $2 \%$ global rise in $\mathrm{CO}_{2}$ emissions was projected for 2018 (Le Quéré et al., 2018), as most countries still vent the vast majority of industrial $\mathrm{CO}_{2}$ waste that they produce into the atmosphere (Figueres et al., 2018). Because of the long residence time of carbon dioxide in the atmosphere, carbon capture and storage (CCS) is viewed by many experts as "a necessity, not an option, for reaching net-zero greenhouse gas emissions" (Stark and Thompson, 2019). CCS pertains not only to hydrocarbon energy consumption, but also to industries such as cement and iron/steel production, which generate $8 \%$ (Lena et al., 2019) and 6-7\% (SETIS, 2019) of global anthropogenic emissions, respectively. CCS is also important in the context of increasing sources of emission such as geothermal power production (Armannsson, 2017),

\footnotetext{
${ }^{*}$ Corresponding author

Email address: apaluszn@imperial.ac.uk (Adriana Paluszny)
} 
and the mining of metals and minerals (Vidal et al., 2013). This latter category includes the mining and recycling of "green minerals" and rare earth elements, such as neodynium, copper, cobalt, and lithium, to meet the accelerated increasing demand of materials for renewable technologies (Vandepaer et al., 2017). In addition, the implementation of hydrogen as a low-carbon fuel for heat in buildings and industrial processes relies on decarbonisation instrumented by CCS (Joffe et al., 2018).

The challenge of limiting or lowering the amount of $\mathrm{CO}_{2}$ in the atmosphere has prompted new strategies that involve emission reduction, including capturing carbon at the industrial source emitters, as well as $\mathrm{CO}_{2}$ utilisation $(\mathrm{CCU}), \mathrm{CO}_{2}$ utilisation and storage (CCUS), and greenhouse gas removal (GGR). These strategies are complementary, and aim to offset both local and remote emissions of $\mathrm{CO}_{2}$. While $\mathrm{CCU}$ is a promising technology, and is favourably perceived (Markewitz et al., 2012; Arning et al., 2019), it targets considerably smaller volumes of greenhouse gases than would be required in order to meet emission targets. CCUS includes subsurface technologies that use $\mathrm{CO}_{2}$ in injection operations, and thereby trap some of the carbon used into the treated formations (Tapia et al., 2018). GGR provides a portfolio of removal strategies, including land-based strategies such as soil carbon storage, subsurface mineral carbonation, and direct air capture and carbon storage (DACCS), which rely on geological storage to accommodate large volumes of gas to be removed from the atmosphere (Rockström et al., 2017). As energy usage continues to increase, emission of $\mathrm{CO}_{2}$ into the atmosphere is unlikely to decline unless a combination of approaches are employed. An example is geothermal energy, which is expected to save around 1000 million tons/year of $\mathrm{CO}_{2}$ emissions. Geothermal power plants, which emit both $\mathrm{CO}_{2}$ and hydrogen sulfide $\left(\mathrm{H}_{2} \mathrm{~S}\right)$ of magmatic origin, will probably need to rely on CCS in future scenarios as the geothermal sector increases in volume and expands into producing systems with relatively high $\mathrm{CO}_{2}$ concentrations (Fridriksson et al., 2011; Bonafin et al., 2019), in some cases with greenhouse gas emission rates even higher than those of coal-fired power plants (Kaya and Zarrouk, 2017).

Captured $\mathrm{CO}_{2}$ can potentially be stored in the deep ocean, injected into reactive rock formations, or injected into depleted reservoirs and saline aquifers (Bickle, 2009); under the right economical conditions, $\mathrm{CO}_{2}$ can also be stored in depleted shale gas reservoirs that have been drained of hydrocarbons (Myshakin et al., 2018). To make a significant impact, the large volumes of $\mathrm{CO}_{2}$ to be captured and stored require a long term, cost-effective, industrial-scale storage solution, which points to the possibility of storing carbon in the very same porous rocks that contained it in the first place. Once injected underground, the mobility of $\mathrm{CO}_{2}$ is reduced by a combination of physical and chemical processes, including trapping by (1) structural and stratigraphic, (2) physical hydrodynamic, (3) and geochemical processes including dissolution and mineral precipitation, leading over time to immobilisation (IPCC Special Report on Carbon Dioxide Capture and Storage, 2005). The importance of these mechanisms varies over time. For the first 100 years the dominant trapping mechanism is structural/stratigraphic - that means on the short term, geomechanics is key to ensuring containment and remains important even on the order of 1000's of years. Geomechanical studies of $\mathrm{CO}_{2}$ injection and storage seek to de-risk CCS and DACCS, and support GGR, by quantifying leakage and induced seismicity risk (Rutqvist, 2012). The latter two points are common concerns when it comes to public perception and acceptance of geological storage of $\mathrm{CO}_{2}$ (Oltra et al., 2010; Seigo et al., 2014a; Xenias and Whitmarsh, 2018). Therefore, fundamental geomechanics research is a necessary first step to help address such concerns.

Carbon capture pilot studies in depleted sites are instrumental in this pursuit, as they aim to identify storage effectiveness and operational constraints, which are considered among the most important feasibility concerns for industrial operators (Vercelli et al., 2017). In addition, depleted pilot sites for storage can validate numerical models that predict subsurface conditions during and after injection, as often caprock and reservoir flow properties have already been characterised to some extent. An important relationship therefore emerges between depleted pilot sites, public perceptions, and geomechanical studies, as they enable and interfere with one another's ability to bring CCS technology to fruition. Just as geoscience is important to ensure the technological feasibility of $\mathrm{CO}_{2}$ storage, public perception is also important to ensure acceptance of a project in the local implementation area, affecting both short and long term viability of a storage site. On one hand, perceived risks are likely to be reduced by pilot sites and appropriate technical assessment, including geomechanical risk assessments. On the other hand, factors impacting the potential for a site to be successful are complex and go beyond perception of risk either from the public, regulators or financiers. Although fundamental geomechanics research does not directly address risk perceptions, it does provide the necessary evidence base for social scientists and science communicators to help address concerns and public acceptance.

This paper explores complex geomechanical factors in fourteen depleted hydrocarbon $\mathrm{CO}_{2}$ storage sites, and the broader context of public perceptions of and concerns about CCS, by considering both scientific and societal aspects 
of geomechanical effects of storage in depleted sites. In the remainder of this section, the wider context is first considered in relation to: (i) depleted reservoirs of relevance, (ii) caprock integrity, $\mathrm{CO}_{2}$ migration and leakage, and (iii) public perception studies. This is followed by consideration of the three geomechanical aspects of interest. Firstly, the characterisation and understanding of Earth materials involved in carbon storage and its success. Secondly, the numerical simulation of scenarios of interest and their impact on our understanding of the process of storage. Thirdly, the public perception of geomechanical aspects of storage, both in the broader context and specific to several of these pilot studies. The three geomechanical perspectives have a strong impact on the ability to de-risk storage, and are intertwined in the way that they impact society, influencing experts, operators, regulators, and the general public. Given that geological storage can generate fear in some members of the public (e.g. Sharp et al., 2009), geoscientists, social scientists and science communicators have often worked to address the underlying causes of such fears, with various approaches dating back at least three decades (see (e.g. Slovic et al., 1991), on geological storage of nuclear waste). As with nuclear storage research where the public is not intimately familiar with nuclear technology, detailed knowledge of $\mathrm{CO} 2$ technologies, or geologies, is not necessary to affect public perceptions. Fundamental as well as applied research is then needed, to address perceptions and misconceptions. However, the amount and granularity of available geological information and methods varies with each storage project, and this is an important shortcoming that this paper aims to address.

\subsection{Carbon storage in depleted reservoirs}

Depleted hydrocarbon reservoirs have a number of advantages for carbon storage. In addition to local trapping mechanisms, storage is supported by a system of impermeable caprocks that once sealed hydrocarbons into place over million-year time scales. Depleted reservoirs provide the volume necessary for storage, have already been geologically characterised, and are, to some extent, equipped with the infrastructure and industrial setup required for fluid injection. Field data are usually available, as the reservoir has been previously studied and monitored (Orlic, 2016). In addition, depleted reservoirs are "brown sites" that have the advantage of having proved to already have stored liquids and gases over long periods of geological time without appreciable leakage.

The study of $\mathrm{CO}_{2}$ storage has developed from a concept technology, to a tested field technique with multiple successful pilot test sites worldwide. Table 1 summarises the characteristics of fourteen depleted reservoir pilot sites developed throughout the world. Prior to 2013, only four large-scale CCS projects had demonstrated the technology, storing approximately $50 \mathrm{MtCO}_{2}$ (CCS Technology Roadmap 2013 edition, IEA). Since then, nine further projects, which together have the potential to capture and store $13 \mathrm{MtCO}_{2}$ per year, should have been operational by 2016. Many of the larger proposed projects have been placed on hold, while others have been cancelled. In many $\mathrm{CO}_{2}$ storage pilot studies, geomechanical-related concerns including induced seismicity, leakage into the groundwater or marine environment, and long-term well integrity, have been cited as major influences on value-cost considerations, safety, and public concerns (Wallquist et al., 2010; Tapia et al., 2018; Gough et al., 2018; Lee et al., 2018). Specifically the fear of leaks, tied to the hydrogeomechanical behaviour of the site, appears to be a common factor of concern across several countries (Ashworth et al., 2013; Whitmarsh et al., 2019). This is despite experience from European projects that has shown that there are "no significant concerns regarding technology, and technology implementation is not considered a major reason for $\left[\mathrm{CO}_{2}\right.$ storage] project progress delays" (Kapetaki et al., 2017). This does, however, highlight the importance of risk (both technical and financial) on barriers to deployment such as liability and social acceptance (Poumadère et al., 2011).

\subsection{Caprock integrity, $\mathrm{CO}_{2}$ migration, and leakage}

A primary aspect of all geological storage options is the requirement of at least one suitable sealing layer above the injection interval (Pires et al., 2011). Long-term integrity of this seal and associated overburden seals is of paramount importance to demonstrating short-term containment, and of secondary importance on long timescales, though still necessary. The interaction between $\mathrm{CO}_{2}$ and sealing lithologies can be complex. For example, mud-rich interbeds can act as a series of baffles to the upward migration of $\mathrm{CO}_{2}$ (Chadwick et al., 2009). Increased certainty around such behaviour is beneficial for constraining expected storage site evolution. In the case of depleted reservoirs, the intended seal is usually the caprock that previously trapped hydrocarbons prior to anthropogenic extraction. In these, the sealing capacity of the caprock has been previously demonstrated, though this does not account for changes to properties and structure resulting from hydrocarbon production activities, or the differing properties of $\mathrm{CO}_{2}$. 


\begin{tabular}{|c|c|c|c|c|c|c|c|}
\hline Site Name & Host Country & Operator & $\mathrm{CO}_{2}$ Source & $\mathrm{CO}_{2}$ Fate & Capture & Volume & Status \\
\hline Snøhvit & Norway & Equinor & LNG Proc. & Depl. Gas & Post & $0.7 \mathrm{Mt} / \mathrm{yr}$ & 2007- \\
\hline Heletz & Israel & EWRE & Various & Depl. Oil & Pre & $<0.5 \mathrm{Mt} / \mathrm{yr}$ & 2016- \\
\hline K12-B & Netherlands & GDF Suez & Gas Proc. & Depl. Gas & -- & $0.2 \mathrm{Mt} / \mathrm{yr}$ & 2004-2006 \\
\hline Schwarze Pumpe & Germany & Vattenfall & Coal & Depl. Gas & Oxy & $13.45 \mathrm{kt} / \mathrm{yr}$ & 2008-2014 \\
\hline Lacq & France & Total/Alstom & Oil/Gas & Depl. Gas & Oxy & $12.75 \mathrm{kt} / \mathrm{yr}$ & 2010-2013 \\
\hline In Salah & Algeria & $\mathrm{BP}$ & Gas Proc. & Depl. Gas & --- & $1.2 \mathrm{Mt} / \mathrm{yr}$ & 2004-2011 \\
\hline Otway & Australia & $\mathrm{CO} 2 \mathrm{CRC}$ & Gas & Depl. Gas & Natural & $0.065 \mathrm{Mt} / \mathrm{yr}$ & 2008-2011 \\
\hline ROAD & Netherlands & E.ON & Coal & Depl. Oil/Gas & Post & $1.1 \mathrm{Mt} / \mathrm{yr}$ & On Hold \\
\hline Magnum & Netherlands & Nuon/Vattenfall & Various & Depl. Oil/Gas & Pre & $8.64 \mathrm{Mt} / \mathrm{yr}^{\gamma}$ & On Hold \\
\hline Peterhead & UK & Shell and SSE & Gas & Depl. Gas & Post & $1 \mathrm{Mt} / \mathrm{yr}$ & Canc. 2015 \\
\hline Teesside LC & UK & Progressive & Coal & Depl. Oil/Gas & Pre & $2.5 \mathrm{Mt} / \mathrm{yr}$ & 2013-Hold \\
\hline Hunterston & UK & Ayrshire Power & Coal & Depl. Gas & Post & $11.5 \mathrm{Mt} / \mathrm{yr}^{\beta}$ & Canc. 2010 \\
\hline Barendrecht & Netherlands & Shell & Oil Refinery & Depl. Gas & Post & $0.4 \mathrm{Mt} / \mathrm{yr}$ & Canc. 2010 \\
\hline FINNCAP & Finland & Fortnum & Coal & Depl. Gas & Post & $1.25 \mathrm{Mt} / \mathrm{yr}$ & Canc. 2012 \\
\hline
\end{tabular}

Table 1: Sites storing $\mathrm{CO}_{2}$ in depleted oil or gas reservoirs, worldwide. The fate of the $\mathrm{CO}_{2}$ refers to the type of reservoir identified for storage; "Depl. Oil" and "Depl. Gas" are depleted oil and gas fields respectively. The capture data indicates the method of retrieval of the $\mathrm{CO}_{2}$ from the fuel source. Post combustion capture removes $\mathrm{CO}_{2}$ from the flue gases using chemical scrubbers such as amines; these would be retrofitted to existing infrastructure. Pre combustion capture removes the $\mathrm{CO}_{2}$ from the fuel via chemical reaction before the combustion has taken place. Pre combustion capture takes place in stages; initially a syngas is created by partially oxidising the fuel in a gasifier. The syngas is reacted with steam to produce $\mathrm{H}_{2}$ and $\mathrm{CO}_{2}$; the $\mathrm{CO}_{2}$ can be captured, whilst the $\mathrm{H}_{2}$ can then be used as a fuel. Oxy-fuel combustion requires the fuel to be burned in oxygen rather than air and the resulting flue gas is almost entirely $\mathrm{CO}_{2}$ and water vapour. Sources of this table include: Carbon Capture and Sequestration Technologies at MIT (2016), Bouzalakos and Mercedes (2010), Gal et al. (2019). ${ }^{\beta}$ Calculated using 1600 MW electricity generation capacity $\times$ $90 \%$ capture $\times 8000$ tonnes $\mathrm{CO}_{2}$ per year per MW electricity generation capacity, following the method of Rai et al. (2008). ${ }^{\gamma}$ Calculated following the method of Rai et al. (2008) using 1200MW electricity generation capacity.

A leak can be defined as a migration event that entails the movement of fluids all the way to the surface. Migration through a fault into the overburden, has the potential to result in at least some $\mathrm{CO}_{2}$ fully progressing to the surface and being released into sea water or the atmosphere. Whilst terrestrial leakage is a possibility for some proposed CCS schemes, for those involving the use of a depleted reservoir, the primary consideration is the impact to leakage into the marine environment. This relates to any potential interaction with the biosphere, including the shallow subsurface and surface ecosystems (Turley et al., 2006). Should migrating $\mathrm{CO}_{2}$ reach the surface, any subsequent leakage is likely to be localised, potentially emerging from discrete point-sources, such as abandoned wells (Boothroyd et al., 2016) or specific faults (Shipton et al., 2004). In a recent study of natural gas reservoirs in Italy (Roberts et al., 2017), only two of nine reservoirs, taken as analogues of $\mathrm{CO}_{2}$ storage sites, were found to leak at the surface. The study found that the leaking reservoirs were located $<10 \mathrm{~km}$ away from modern extensional faults, and the sealing reservoirs were all found to have elevated overburden pressures (Roberts et al., 2017). This study also measured the leakage rates primarily through faults and fractures.

Public support is crucial for onshore (Kapetaki et al., 2017) and offshore projects alike. Leaks from an offshore storage site might affect local ecosystems, and the economy of local fisheries, by altering $\mathrm{pH}$ with accompanying physiological effects (Turley et al., 2006). Relevant timescales are substantially longer than those required for many other environmental assessments and involve, not just the injection period, but also post-closure over hundreds of years (Krüger et al., 2011; Rastelli et al., 2016). Nevertheless, recent work has suggested that concerns such as acidification, changes in biological diversity and species composition (Rodríguez-Romero et al., 2016), may only become relevant at unlikely high $\mathrm{CO}_{2}$ concentrations, and may result in only short-term impacts on local fauna (Amaro et al., 2018).

Geomechanical studies can aid the assessment of caprock integrity and can facillitate in the monitoring or mitagation of $\mathrm{CO}_{2}$ migration above the caprock. Geomechanical studies include the characterisation of mechanical properties of sealing rocks (discussed in Section 3), and the numerical modelling of damage and fracture growth leading to changes in permeability of the caprock, fault displacement leading to seismicity, and thermal stresses (discussed in Section 4). Geomechanical studies are primarily focussed on constraining the mechanical deformation of the caprock and other potential migration pathways, such as pre-existing faults, shrinkage fractures, and pre-existing sealed boreholes. Mechanical behaviour can then be used to constrain subsurface observations of migration and loss of integrity. Fluids migrating through a storage reservoir can potentially trigger shallow microseismic events that can be monitored 
from the ground surface (Mitchell and Green, 2017). Detection of the microseismic signals and mechanical deformation of the reservoir can help to build a picture of subsurface processes (Boreham et al., 2011), and the migration of injected fluids in the reservoir can be modelled (e.g. Estublier and Lackner, 2009). The geomechanical response of a reservoir can be continuously modelled prior to and during injection (Salimzadeh et al., 2018a) to understand how the injected $\mathrm{CO}_{2}$ remains trapped in the subsurface. An important factor that influences mechanical failure of a shale rock is the relative quantity of "soft" components, such as clay and kerogen, and "stiff" components, such as quartz, feldspar, pyrite and carbonates, in the shale caprock (Sone and Zoback, 2013a,b). This has been shown for caprocks, where either fracture growth is promoted or, in some cases, crack healing is induced (Kim and Kemeny, 2009). And in the case of low permeability mudrocks, key influencing factors on the permeability of the caprock include initial stress conditions, stress path gradient and caprock strength heterogeneity (Harrington et al., 2018). Fracture growth can, under brittle conditions, also increase the permeability of the caprock, depending on the mechanical properties of the rock and the in situ stresses, as well as the fracture density and spacing (Lang et al., 2014, 2018). Therefore, for assessing the probability of fracture growth on the caprock seal, it is necessary to incorporate accurate fracture growth predictions into a numerical model (Salimzadeh et al., 2018a).

\subsection{Public perception studies}

Potential $\mathrm{CO}_{2}$ leakage also features among public concerns (Wallquist et al., 2010; Seigo et al., 2014b; Gough et al., 2018). A review of the CCS perception literature found that, consistent with other new technologies, benefit perceptions (personal and societal) were the strongest predictor of CCS acceptance (Seigo et al., 2014b; Wallquist et al., 2012; Howell et al., 2014; Krause et al., 2013; Schumann et al., 2014; Warren et al., 2014; Braun et al., 2018). While CCS offers environmental and economic benefits, it can be controversial across cultures in terms of both risk perception and benefit perception, influenced to some extent by cultural dimensions, such as uncertainty avoidance and society's long- vs. short-term orientation (Karimi and Toikka, 2018). It has met high-profile public opposition to particular CCS developments (Oltra et al., 2012), and strong regulatory frameworks currently control its development. The latter could also be regarded as an indirect expression of public concern about carbon storage. An example of regulatory mechanisms controlling CCS is the European Directive on the geological storage of $\mathrm{CO}_{2}(2009 / 31 / \mathrm{EC})$, which calls for the operator to demonstrate that $\mathrm{CO}_{2}$ will be "completely and permanently contained". The directive also outlines three criteria that must be met to demonstrate this: "(i) the conformity of the actual behaviour of the injected $\mathrm{CO}_{2}$ with the modelled behaviour, (ii) the absence of any detectable leakage, and (iii) that the storage site is evolving towards a situation of long-term stability". Such risk-averse regulation at the highest level might reflect political will to alleviate public concern to a new technology (Burgess and Chilvers, 2006).

Demonstration of effective storage is tied to the ability to monitor the environment, and predict the flow and mechanical behaviour of the reservoir during and after injection. From a geomechanical point of view, effective CCS is largely dependent on the caprock's mechanical stability (Karimnezhad et al., 2014), and on the ability to correctly model and predict subsurface deformation and $\mathrm{CO}_{2}$ migration using numerical and analytical models, both at short and long time scales. Pilot sites in depleted reservoirs play an important role in providing insights into the technology, as well as valuable data to validate predictive models, used for subsurface planning and industrial de-risking of the technology. These pilot sites also expose regulatory and societal expectations of the technology (Kapetaki et al., 2017), serving to shape the type of test and quantifications that are developed to understand requirements for its successful deployment.

Success of a CCS project is also linked to public perception of its capability to become a potential instrument to decrease carbon emissions at an industrial scale (IPCC and Climate Change, 2014; IEA, 2013). Alongside economic and regulatory criteria, public acceptance of CCS is an important precondition for its implementation (RCUK, 2010; Wennersten et al., 2015; van Alphen et al., 2007). Public concerns about CCS do not usually discriminate between types of geological $\mathrm{CO}_{2}$ storage, yet it is important to understand and address successfully the concerns at an early stage at each specific site. It is crucial to provide evidence to the public that CCS can be an effective instrument that can form part of a wider strategy for achieving significant cuts in $\mathrm{CO}_{2}$ emissions. Further public acceptance may be gained by viewing CCS as a transition technology while renewable energy technology and increased energy efficiency measures are being developed as well as serving as a solution for industries, such as steel and cement, that are difficult to power from clean sources (Shackley et al., 2004; van Alphen et al., 2007; Duetschke et al., 2016; Upham and Roberts, 2011a). 
Recognising climate change as a problem, and trust in the ability of industry to develop CCS projects, as well as demographic factors -age, gender, education, and political values- are crucial factors driving acceptance (Poumadère et al., 2011; de Best-Waldhober et al., 2011; Terwel et al., 2011, 2012; Carley et al., 2012; Ashworth et al., 2014, 2015; Gough et al., 2014; Lofstedt, 2015). Seigo et al. (2014b) conclude that trust plays a particularly important role for benefit perception in the case of CCS, and benefit perception is the best predictor of acceptance of CCS. Academics, followed by government and then industry, are most trusted in the UK (Roberts and Mander, 2011), and environmental NGOs are also more trusted than industry (Terwel et al., 2011). Trust can be engendered better through face-to-face contact with experts and developers; this can be done better through citizens panels than via printed/online materials (Poumadère et al., 2011; Chrysostomidis et al., 2013), as well as through substantively involving communities in decision-making (Terwel et al., 2011), as the engagement process can profoundly influence community perceptions of CCS (Oltra et al., 2012; Duetschke, 2011; Buhr and Wibeck, 2014; Brunsting et al., 2015). In addition to benefits perception, trust is also critical to how information on CCS is perceived; in turn, this is related to the perceived competence and integrity of the source (Vercelli et al., 2013).

Another factor linked to the perception of storage site integrity is long-term liability, which is of particular concern to operators and investors. Liability in this context is related to both the perception of and expected magnitude of risk associated with long-term containment. Specifically, liability includes any damages that can be related back to the leakage, the cost to stop and mitigate any leaks, and any associated international or local sanctions that may have been, or will be, legislated at present or at a future time (Zapantis et al., 2019). This directly influences pilot sites and the development of $\mathrm{CO}_{2}$ as a technology, as it strongly influences finance and insurance structures required for the success of these projects (Gomersall et al., 2018; Zapantis et al., 2019). Governments can incentivise $\mathrm{CO}_{2}$ storage by minimising operator/investor concerns around liability. A range of mechanisms have been adopted or are under consideration, including capping financial risk, or liability transfer to government in the long-term, recognising that the risk of leakage decreases after injection, and continues to decrease with time (Gomersall et al., 2018; Zapantis et al., 2019). Nevertheless, confidence in storage integrity is key to minimising the real and perceived risks associated with any remaining liability. According to the review conducted by Seigo et al. (2014b) the most important risks people perceive regarding CCS are that it may displace investment in renewable energy, and that CCS may lead to leakage or overpressurisation of the $\mathrm{CO}_{2}$ storage formation. The latter is directly related to the "geomechanical perspective" of storage, and can be addressed by careful assessment of geomechanical integrity at proposed sites. This includes sitespecific rock characterisation as well as numerical and analytical studies examining the potential for $\mathrm{CO}_{2}$ migration, combined with careful monitoring during injection to confirm conformity to expected behaviour and a move towards system equilibration and stability. Lessons and understanding derived from pilot sites are invaluable for informing such work.

\section{Pilot sites of $\mathrm{CO}_{2}$ storage in depleted reservoirs}

The majority of CCS pilot projects worldwide are for enhanced oil recovery (EOR) and enhanced gas recovery (EGR), or have utilised saline aquifers as the destination for the injected $\mathrm{CO}_{2}$ (Herzog, 2016). However, there have been at least fourteen pilot studies to inject $\mathrm{CO}_{2}$ into a depleted hydrocarbon reservoir (Table 1). Four hosted by the Netherlands (Barendrecht, K12-B, ROAD and Magnum), three by the UK (Hunterston, Peterhead, and Teesside Low Carbon), and the remaining projects hosted by Finland (FINNCAP), Germany (Schwarze Pumpe), France (Lacq), Norway (Snøhvit), Israel (Heletz), Algeria (In Salah) and Australia (Otway). Most of these projects are not currently operating, and are no longer receiving $\mathrm{CO}_{2}$, except for Snøhvit and Heletz, either because their operational lifespan has completed (K12-B, Schwarze Pumpe, Lacq, In Salah, and Otway), or they are on hold (Teesside Low Carbon, ROAD, Magnum and Peterhead), or they have been definitively cancelled (Barendrecht, FINNCAP and Hunterston). Table 1, which summarises the presented depleted reservoir pilot sites, highlights that while many of the pilot sites were cancelled or placed on hold, others successfully completed operational periods, and two are still ongoing.

\subsection{Active Projects}

Sn $\phi$ hvit. In this Norwegian project, the natural gas produced from three offshore hydrocarbon reservoirs (Snøhvit, Askeladden and Albatross) is stripped of the $\mathrm{CO}_{2}$ at an LNG plant, which is subsequently re-injected into a saline aquifer at the edge of the Snøhvit gas reservoir at a depth of $2.7 \mathrm{~km}$, part of the same formation (Estublier and Lackner, 
2009). The 45-75 m thick Tubaen formation predominantly comprises two sandstone units on either side of a shalerich interval (Gao, 2013); coals are also present. The permeability and porosity of the Tubaen formation are 10-16\% and 1.28-8.68 $\times 10^{-13} \mathrm{~m}^{2}$, respectively (Maldal and Tappel, 2003). The site can store up to $0.7 \mathrm{Mt}$ per year, and as of June 2017, more than 4 million tonnes of $\mathrm{CO}_{2}$ have been stored at Snøhvit since the start of the injection in 2008. Geomechanical studies include understanding fault reactivation (Chiaramonte et al., 2011), geomechanically-driven changes to permeability during injection (Hansen et al., 2013), and the study of in situ 3D fracture network properties and their influence on fault permeability (Wennberg et al., 2008).

Heletz. The Heletz pilot $\mathrm{CO}_{2}$ injection site has been developed in the framework of several EU projects (MUSTANG, PANACEA, TRUST). This site is part of the Heletz oil field, discovered in 1955, and is located in the Southern Mediterranean Coastal Plain of Israel (Niemi et al., 2016). This is a scientifically motivated site with the objective of gaining understanding of the various $\mathrm{CO}_{2}$ transport and trapping processes and their quantification and monitoring, rather than a site intended for actual $\mathrm{CO}_{2}$ storage. The geomorphological characteristics of Heletz, namely, that it has saline edges where no oil was discovered, along with the relatively thin caprock and fault locations, make it ideal for testing injection scenarios. The reservoir is located at a depth of around $1.6 \mathrm{~km}$, and comprises a limestone and three lower-Cretaceous high permeability sand layers, with a total thickness of $10 \mathrm{~m}$. It is sealed by a low permeability shale and marl caprock layer of $40 \mathrm{~m}$ thickness, and is intersected by two pre-existing sub-vertical normal faults (Niemi et al., 2016). The injection experiments carried out have focussed on quantifying capillary/residual trapping. The project met no public opposition, and was supported by the regulating authorities, including the Israel Water Authority, Ministry of Science, Ministry for the Protection of the Environment, and Ministry of Energy.

\subsection{Completed Projects}

K12-B. This North Sea project, which operated between 2004 and 2006, was designed to remove $\mathrm{CO}_{2}$ from a $\mathrm{CO}_{2}-$ rich natural gas at the extraction location, and return it to the same reservoir from which it came, simultaneously studying $\mathrm{CO}_{2}$ storage and migration pathways in the reservoir (der Meer et al., 2005). The storage reservoir is the Rotliegend sandstone, located $3.8 \mathrm{~km}$ below the North Sea. The project was motivated by a need to remove the $\mathrm{CO}_{2}$ from natural gas before transporting it back to the Netherlands, because $\mathrm{CO}_{2}$ concentrations were above the acceptable limit for the pipeline. Re-injecting at the same site removed the need for transportation of the removed $\mathrm{CO}_{2}$. The project comprised three stages: an initial feasibility study (Phase 1), a pilot study (2004-2005) with two periods of $\mathrm{CO}_{2}$ injection into the reservoir to trace the migration pathways and investigate the potential for EGR (Phase 2), and an upscaling to industrial-scale $\mathrm{CO}_{2}$ storage (Phase 3). Phase 3 of the project, which focused on upscaling, has yet to take place.

Schwarze Pumpe. This project was supported by Vattenfall and Gaz de France, and was designed to test both oxyfuel combustion and post-combustion capture processes, with the captured $\mathrm{CO}_{2}$ being stored in a depleted gas field. The Altmark depleted gas field was originally identified as the storage location for the liquefied $\mathrm{CO}_{2}$ produced at Schwarze Pumpe (Strömberg et al., 2009). However, a combination of the shortcomings of federal $\mathrm{CO}_{2}$ storage legislation and public protesting contributed to the cancellation of storage at Altmark (Zero Emission Resource Organisation, 2016). This led to the identification of pilot site Ketzin for the $\mathrm{CO}_{2}$ storage. $\mathrm{CO}_{2}$ injection at Ketzin was operated by GeoForschung Zentrum Potsdam between June 2008 and August 2013, with more than $67 \mathrm{kt} \mathrm{CO}_{2}$ stored (Ouellet et al., 2011). In 2014, Vattenfall announced a decrease in their research and development budget, with all research into CCS to be discontinued. The Vattenfall CCS project was abandoned partly due to "popular opposition based on environmental fears" as it was tied to the continued production of increasingly cheap coal, citing lack of political will as one of the main obstacles for CCS development in Germany (Reuters, 2011).

Lacq. This pilot project was the first CCS chain in Europe, covering all steps from capture to storage, operated between 2011 and 2013, and was designed as a research experiment. The project combined oxyfuel combustion of gas to obtain a flue gas stream of only steam and $\mathrm{CO}_{2}$. This $\mathrm{CO}_{2}$ was then transported $27 \mathrm{~km}$ to the Rousse depleted gas field, and sequestered at $4.5 \mathrm{~km}$ depth (Pourtoy et al., 2013). A finite amount of $\mathrm{CO}_{2}$ was injected (51 kilotonnes); this $\mathrm{CO}_{2}$ was then monitored for a period of five years to ascertain that the gas would be successfully trapped in the subsurface. A number of geomechanical studies were supported by this project, including seal integrity (Pourtoy et al., 2013), microseismic monitoring (Lescanne et al., 2011), as well as wellbore effects and long term $\mathrm{CO}_{2}$ migration 
(Thibeau et al., 2013). The project had a favourable economic and social context (Ha-Duong et al., 2011), and was successful, validating oxy-combustion for carbon capture, and demonstrating that $\mathrm{CO}_{2}$ could be stored in an onshore depleted gas reservoir. Soil analysis at Lacq measuring $\mathrm{CO}_{2}$ concentration levels during and after injection at the site yield no indication of leakage up to date (Gal et al., 2019).

In Salah. This Algerian project involved stripping $\mathrm{CO}_{2}$ from natural gas being produced from seven proven gas reservoirs in the $20 \mathrm{~m}$ thick Krechba carboniferous sandstone reservoir, located $1.9 \mathrm{~km}$ under the southern part of the Sahara desert; $\mathrm{CO}_{2}$ was then re-injected into the water-leg of the reservoir at a rate of up to $50 \mathrm{mmscf} /$ day (Verdon et al., 2015). The reservoir has an anticline structure, with a porosity and average permeability of 13-20\% (Verdon et al., 2015) and $10 \mathrm{mD}$ (Mathieson et al., 2011), respectively. The storage reservoir is sealed by a sequence of carboniferous mudstones nearly $1 \mathrm{~km}$ thick (Wright, 2007). Injection at In Salah stopped because of the identification of increased levels of risk relating to the vertical leakage of $\mathrm{CO}_{2}$ into the caprock (Ringrose et al., 2013). Quantified risk assessments were regularly conducted based on new seismic and satellite data, as well as geomechanical modelling (Ringrose et al., 2013). In 2010, seismic data from 2009 allowed the identification of linear features which, alongside analysis of InSAR data, suggested the possibility that the caprock was being inadvertently hydrofractured (Ringrose et al., 2013). This led to the reduction of the $\mathrm{CO}_{2}$ injection pressure, and injection was suspended in 2011.

Otway. The Otway Project initiated in 2008, after four years of searching for a suitable geological site (Jenkins et al., 2012a). It became Australia's first geological $\mathrm{CO}_{2}$ storage project (Steeper, 2013), with the aim of undertaking $\mathrm{CO}_{2}$ storage research at the same time as executing a $\mathrm{CO}_{2}$ storage trial (Tenthorey et al., 2014). In Stage 1 of the project (2008-2009), 65,000 tonnes of $\mathrm{CO}_{2}$ were injected into the structural trap of the depleted gas field (the Waare$\mathrm{C}$ Formation reservoir) (Paterson et al., 2013) at a depth of approximately $2 \mathrm{~km}$, demonstrating successful storage of $\mathrm{CO}_{2}$ and in situ monitoring (Hortle et al., 2011). The porosity and average permeability of the Waare $\mathrm{C}$ formation are 10-28\% (Dance, 2013) and $2700 \mathrm{mD}$ (Mehin and Constantine, 1999), respectively. The formation caprock is the 25-30 m thick Belfast Mudstone, which has a porosity of $15 \%$ and permeability of less than $1 \mathrm{mD}$ (Dance, 2013). The second stage of the Otway project (2011 onwards) involved the injection of $\mathrm{CO}_{2}$ at $1.3 \mathrm{~km}$ depth into the tilted saline Paaratte formation (Tenthorey et al., 2014). This lithologically heterogeneous formation has no apparent structural trap (Paterson et al., 2013). The trapping mechanism relates to the carbonate cement layers within the reservoir that block the pore space and decrease the permeability. The goal of Stage 2 of the Otway Project was to improve the understanding of migration and trapping mechanisms in saline formations (Watson et al., 2012).

\subsection{On-Hold Projects}

The following four projects have all been placed on hold at different stages in their planning, before $\mathrm{CO}_{2}$ capture and storage could begin. On-hold projects include two sites in the Netherlands, and two in the United Kingdom.

$R O A D$. The Rotterdam Capture and Storage Demonstration project, Rotterdam Opslag en Afvang Demonstratieproject (ROAD), was designed to operate retrofitted post-combustion capture of $\mathrm{CO}_{2}$ from a new coal fired power plant. It aimed to use an existing onshore to offshore pipeline, and store the sequestered $\mathrm{CO}_{2}$ in a depleted North Sea gas reservoir (Read et al., 2014). In 2009, 180 million euros was granted by the EU, within the Government Economic Energy Programme for Recovery, supplemented in 2010 by 150 million euros from the Government of the Netherlands (Kapetaki et al., 2017). The project has contended with a number of obstacles including permitting, commercial negotiations, and funding. Capture and storage permits are now in place and are definitive and irrevocable (Kapetaki et al., 2017). A further five million euros were committed by the Global Carbon Capture and Storage Institute (GCCSI). ROAD was planned to start in 2015, but has since been placed on hold due to lack of funding (Arts et al., 2012). A recent public perception study of ROAD and other pilot sites found that technical, legal, financial, and social barriers are largely interdependent, and that financial barriers are much more important than the others (Sara et al., 2015). Financial barriers depend, in turn, on geomechanical studies, as these feed into the quantification of leakage risk and long-term damage liability of the sites.

Magnum. The Nuon Magnum capture and storage project was designed to use a multi-fuel pre-combustion technology (coal, gas and biomass) with $\mathrm{CO}_{2}$ storage in offshore North Sea oil and gas fields. The Magnum project built on the successful Buggenum IGCC pilot plant test (with Shell), and Shell's Coal Gasification Process was to be implemented for the pre-combustion capture (van Dijk et al., 2014). Nuon also appointed Mitsubishi Heavy Industries to 
deliver the gas-fired part of the power plant. In 2011, the project was put on hold, and the coal gasification technology was postponed to 2020 due to both rising coal prices and opposition from environmental campaigners (Damen et al., 2014). Additional problems with storage location as a result of the Dutch law banning onshore $\mathrm{CO}_{2}$ storage have contributed to the project's uncertainty. The Magnum gas plant is now destined to be converted into a hydrogen-powered plant, extracting hydrogen from natural gas, aiming to capture and store $\mathrm{CO}_{2}$ by 2020 (Barrett, 2017).

Peterhead (Goldeneye). The Peterhead project was a joint venture between Scottish and Southern Energy (SSE) and Shell participating in the UK government's Department of Energy and Climate Change (DECC) £1bn CCS commercialisation competition (Spence et al., 2014). The DECC competition's aim was to develop and fund a full-scale CCS pilot project before 2020; the competition was conceived in 2007 and launched five years later with $£ 1$ bn available in capital funding (MacNeil et al., 2016) and Contracts for Difference (CfDs) then offered as a source of further support. The Peterhead project involved retrofitting post-combustion $\mathrm{CO}_{2}$ capture to an existing Combined Cycle Gas Turbine (CCGT) power station. The planned offshore storage location was the Goldeneye Gas Field in the North Sea, for which existing onshore to offshore pipeline infrastructure was available. The UK's first licence for geological $\mathrm{CO}_{2}$ storage was provided in 2012, and a lease was signed by the crown estate. In 2013, the Peterhead project was chosen as one of two preferred bidders in the CCS competition (Spence et al., 2014) alongside the White Rose Project in North Yorkshire (Capture Power). The preferred projects were given financial backing to conduct Front End Engineering Design (FEED) studies. These studies represented a significant step towards developing major infrastructure projects. In 2014, the UK secretary of state made an agreement with Shell to implement the FEED phase and ensure that the design was fully refined, cost certainty was optimised and technical risks fully reduced ahead of any final investment decisions. In 2015, shortly before the award of the $£ 1$ bn CCS competition was finalised, the UK government announced that the competition would be cancelled and the funding withdrawn (MacNeil et al., 2016).

Teesside Low Carbon. The Teesside Low Carbon Project was a pre-combustion coal gasification project devised by a consortium of industry partners led by Progressive Energy competing in the UK government's DECC £1bn CCS competition. The project involved the advanced separation of coal into $\mathrm{CO}_{2}$ and hydrogen-rich synthesis gas (syngas) before the $\mathrm{CO}_{2}$ could be transported through the North East CCS Transport Network, part of a new National Grid Carbon pipeline. The storage location was identified as a Central North Sea depleted oil field (Lipponen et al., 2017), specifically the Captain and the Bunter Aquifers (Teesside Collective UK, 2015), which were also investigated geomechanically in the context of the Goldeneye field and the Peterhead project. In 2013, the Teesside Low Carbon Project was not selected as one of the two finalists of the UK government's DECC CCS competition, and was instead placed on a reserve list. The community of the Teesside area is largely accepting of CCS technology, which is perceived as a local opportunity for growth (Gough et al., 2018). Teesside, while currently on hold, is an excellent potential pilot site for a $\mathrm{CO}_{2}$ Central North Sea storage hub (Brownsort et al., 2016).

\subsection{Cancelled Projects}

Three of the projects using depleted reservoirs have been cancelled altogether. Two of these, Barendrecht and Hunterston, experienced strong opposing sentiment from local populations, whereas the other experienced financial issues that ultimately prevented it from progressing.

Hunterston. Ayrshire Power's Hunterston project was planned to include a carbon capture facility at a new coal-fired Hunterston power station, and to store $\mathrm{CO}_{2}$ in depleted gas reservoirs in the East Irish Sea (Coulthurst et al., 2011). The Hunterston project was a contender for the UK's CCS commercialisation competition, with backers from both Denmark (the power company Dong Energy - now Ørsted) and the UK (the property firm Peel Holdings). Hunterston faced some local opposition based on factors involving siting and efficiency, and the fact that the project would 'enable' and 'lock-in' coal production in the local area (Mabon et al., 2014). This did not translate into a rejection of CCS as a carbon-storage technology, instead it was interpreted as a rejection of this specific project. As a consequence of the timing of the economic slowdown, in June 2012 Ayrshire Power withdrew the planning application, citing funding uncertainties as the cause of the decision. 
Barendrecht. The Barendrecht project was devised for $\mathrm{CO}_{2}$ injection into depleted gas reservoirs beneath Barendrecht near the port of Rotterdam (Brunsting et al., 2011; Terwel et al., 2012). The initial injection phase was due to begin in 2013, with three years of $\mathrm{CO}_{2}$ injection at $1700 \mathrm{~m}$ depth, followed by twenty-five years of injection at a greater depth of $2700 \mathrm{~m}$ (Herzog, 2016). The aim was to store $\mathrm{CO}_{2}$ from the Pernis Oil Refinery in close proximity to the storage site (Feenstra et al., 2010; Kuijper, 2011). The intended storage location was located beneath a densely populated area, and it was recognised early on that public perception would be important to the success of the project (Kuijper, 2011). Barendrecht would have been the first onshore $\mathrm{CO}_{2}$ storage project in the Netherlands (van Eijs et al., 2011). However, poor communication of the proposed plans to the local population, combined with a resentment towards government pushing industrial projects onto rural areas, caused strong public opposition which ultimately derailed the project.

FINNCAP. The FINNCAP-Meri Pori CCS Project was a proposal by the Finnish power generation companies Fortum and Teollisuuden Voima (TVO) to jointly develop a carbon capture and storage solution for the Meri-Pori power plant by 2015 (Iso-Tryykäri et al., 2011). The project, which had planned to capture and store more than 1.2 million tonnes of $\mathrm{CO}_{2}$ per year in the Danish North Sea, had hoped to be one of the European Commission's twelve large-scale CCS demonstration projects up and running by 2015. Fortum had been testing $\mathrm{CO}_{2}$ capture at its Värtan CHP power plant in Stockholm, Sweden since 2007. The joint venture planned to retrofit post-combustion technology supplied by Siemens Energy, to treat 50\% of the plant's flue gases at full capacity, with a target capture rate exceeding $90 \%$. Unfortunately, in October 2010 Fortum announced that the project had been abandoned due to company strategy and the outcome of 'various studies'. TVO had already withdrawn from the project earlier that year.

\section{Characterisation of rocks at depleted sites}

Analytical and numerical methods quantify the likelihood of $\mathrm{CO}_{2}$ migration from storage sites by evaluating the mechanical and transport behaviour of caprocks. These studies rely on awareness of physical properties at depth (Li and Laloui, 2017), as well as the environmental conditions in situ. To perform numerical studies of the thermohydro-mechanical behaviour of the caprock during injection, fluid and mechanical properties of both reservoir and caprock must be characterised. While reservoir flow data tend to be highly characterised at pilot sites in depleted reservoirs (Rutqvist et al., 2010; Saeedi et al., 2011; Shell, 2011; Saeedi and Rezaee, 2012; Norden and Frykman, 2013), rock mechanical properties at the same sites (e.g. Marbler et al., 2013; Klapperer et al., 2013a) are less readily available. In particular, transport and mechanical properties of caprock materials are even less commonly reported. Tables 2 and 3 report most reservoir and caprock properties available in the literature for the studied pilot sites, and highlight this disparity. In addition to the lack of geomechanical measurements of caprock properties, some of these reported values are not directly measured from core samples, and in some cases the source of the data is unclear. In addition, some of the measurements (applicable to both mechanics and fluid data) may have not been made under true reservoir conditions, and may not capture natural in situ variability of properties. This highlights the need to improve the characterisation of caprocks, but also to conduct numerical simulations that explore the effect of caprock mechanical properties, and their spatial variation, on predictions of leackage and induced seismicity. Field data is not only instrumental in informing and calibrating models, it also drives process understanding and numerical modelling as a unifying approach to redress uncertainty and thus help to build public confidence.

Experimental techniques measuring reservoir and caprock properties in the laboratory allow the prediction of in situ behaviour. A range of methodologies allow the assessment of (i) mechanical behaviour/properties, including uniaxial/triaxial compressive strength, volumetric strain evolution, elastic moduli and Poisson's ratio; and (ii) transport behaviour/properties as a function of effective stress, including void ratio/porosity and intrinsic hydraulic permeability. These properties can vary widely. For example, hydraulic permeability can range between $10 \times 10^{-12} \mathrm{~m}^{2}$ and $10 \times 10^{-23}$ $\mathrm{m}^{2}$ for porous sandstones and tight caprocks, respectively (Neuzil, 1994; Wang, 2000; Tanikawa and Shimamoto, 2009; Armitage et al., 2016; Harrington et al., 2018). These values in clays, shales, and unconsolidated sands are also highly sensitive to the stress state (Nguyen et al., 2014; Ewy, 2019). Laboratory-scale testing provides a useful tool for examining the hydromechanical response of storage site materials to the stress changes that result from depletion, and the subsequent reinflation that occurs during storage. Testing at laboratory scale cannot capture the full field scale and in situ variability of properties. Therefore, careful projection of laboratory values to the reservoir scale is required as part of the characterisation process. 


\begin{tabular}{|c|c|c|c|c|c|c|c|c|c|c|c|c|c|}
\hline Project name & Storage site & Age & rock type & Formation name & $\begin{array}{l}\text { thickness } \\
\text { (m) }\end{array}$ & $\begin{array}{l}\text { capacity } \\
(\mathrm{Mt})\end{array}$ & $\begin{array}{l}\text { depth } \\
\text { (m) }\end{array}$ & $\phi(\%)$ & $K\left(\mathrm{~m}^{2}\right)$ & $E(\mathrm{GPa})$ & $v$ & \multicolumn{2}{|c|}{ UCS (MPa) } \\
\hline Snøhvit & Snøhvit Field & Mid Jurassic & $\begin{array}{l}\text { Fluvial Sand- } \\
\text { stone }\end{array}$ & Tubaen Fm. & $45-75$ & $31-40$ & 2700 & $\begin{array}{l}7-20 \\
14-17\end{array}$ & $0.1-8 \times 10^{-13}$ & 9.6 & 0.3 & - & - \\
\hline Heletz & Heletz & Lower Cretaceous & $\begin{array}{l}\text { sandstone regres- } \\
\text { sive - transgres- } \\
\text { sive deposition }\end{array}$ & Heletz sand & 21 & $\approx 10-20$ & $\begin{array}{l}1200- \\
1400\end{array}$ & $18-22$ & $1-7 \times 10^{-13}$ & $4.8-5$ & 0.2 & - & - \\
\hline K12-B & Leman Gas Field & $\begin{array}{l}\text { Late Carboniferous- } \\
\text { Permian }\end{array}$ & $\begin{array}{l}\text { Aeolian Sand- } \\
\text { stone }\end{array}$ & Rotliegend Sandstone & $<275$ & - & 2000 & $12-23$ & $3.5 \times 10^{-10}$ & $15-20$ & 0.25 & 34.1 & - \\
\hline Schwarze Pumpe & Ketzin & Upper Triassic & Sandstone & Stuttgart Fm. & $40-70$ & - & $630-650$ & $5-35$ & $0.002-5 \times 10^{-12}$ & - & - & $8.1-177$ & - \\
\hline Lacq & Rousse Gas Field & Jurassic & Carbonate & Mano Dolomite Fm. & - & 0.12 & 4500 & $2-4$ & $<1 \times 10^{-15}$ & $1-2$ & $\begin{array}{l}0.15- \\
0.33\end{array}$ & - & - \\
\hline In Salah & $\begin{array}{l}\text { Krechba Gas } \\
\text { Field }\end{array}$ & Carboniferous & Sandstone & Tournasian Sandstone & 20 & 17 & $\begin{array}{l}1850- \\
1900\end{array}$ & & $1.3 \times 10^{-14}$ & 6 & 0.2 & - & - \\
\hline Otway & Naylor Field & $\begin{array}{l}\text { Late Cretaceous (91- } \\
89.5 \mathrm{Ma})\end{array}$ & $\begin{array}{l}\text { Coarse-grained, } \\
\text { beach-barrier } \\
\text { sandstone }\end{array}$ & Waarre Fm. Unit C & $25-40$ & - & $\begin{array}{l}1980- \\
2180\end{array}$ & 23 & $1-4.93 \times 10^{-12}$ & 12 & $\begin{array}{l}0.22- \\
0.33\end{array}$ & 21,210 & \\
\hline ROAD & $\begin{array}{l}\text { P18-4 depleted } \\
\text { reservoir }\end{array}$ & Triassic & $\begin{array}{l}\text { Lower Germanic } \\
\text { Triassic Grp., } \\
\text { Main Buntsand- } \\
\text { stein Subgrp. }\end{array}$ & $\begin{array}{l}\text { Hardegsen, } \\
\begin{array}{l}\text { Detfurth, } \\
\text { Detfurth, and } \\
\text { priehausen }\end{array}\end{array}$ & $30-100$ & 35 & 3500 & $\begin{array}{l}5,9- \\
12,23- \\
28\end{array}$ & $\begin{array}{l}3.5 \times 10^{-13},(100- \\
200,0.2-1) \times 10^{-7}\end{array}$ & $20-25$ & 0.2 & - & 36.1 \\
\hline Peterhead & Goldeneye Field & Cretaceous & Sandstone & Captain Sandstone & $\begin{array}{l}<100 \\
>200\end{array}$ & $10-15$ & 2600 & $28-35$ & $\begin{array}{l}1 \times 10^{-11} \\
6 \times 10^{-13}\end{array}$ & $6.2-10$ & $0.05-0.1$ & - & - \\
\hline Barendrecht & $\begin{array}{l}\text { Barendrecht } \\
\text { (Ziedewij) }\end{array}$ & Triassic & Bunter Sandstone & $\begin{array}{l}\text { Rot Fm., Solling Fm., } \\
\text { Main Buntsandstein } \\
\text { Subgrp. }\end{array}$ & - & 9.5 & $\begin{array}{l}1700 \\
(2700)\end{array}$ & $21-27$ & $1 \times 10^{-6}-1 \times 10^{-9}$ & 6.4 & - & $11-48$ & $4-60$ \\
\hline Hunterston & $\begin{array}{l}\text { East Irish Sea } \\
\text { Hamilton Oil//Gas }\end{array}$ & Triassic & $\begin{array}{l}\text { Aeolian/ fluvial } \\
\text { sandstones }\end{array}$ & $\begin{array}{l}\text { Sherwood Sandstone } \\
\text { Grp. Ormskirk Sand- } \\
\text { stone }\end{array}$ & $<450$ & - & $\begin{array}{l}690- \\
1200\end{array}$ & $12-20$ & $1 \times 10^{-8}-5 \times 10^{-13}$ & - & 0.3 & - & - \\
\hline
\end{tabular}

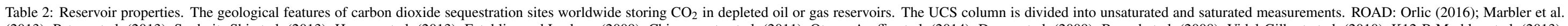

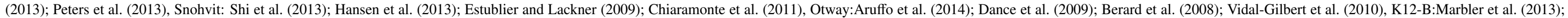
Orlic et al. (2011b). Heletz: Edlmann et al. (2016); Elhami et al. (2016); Niemi et al. (2016). 


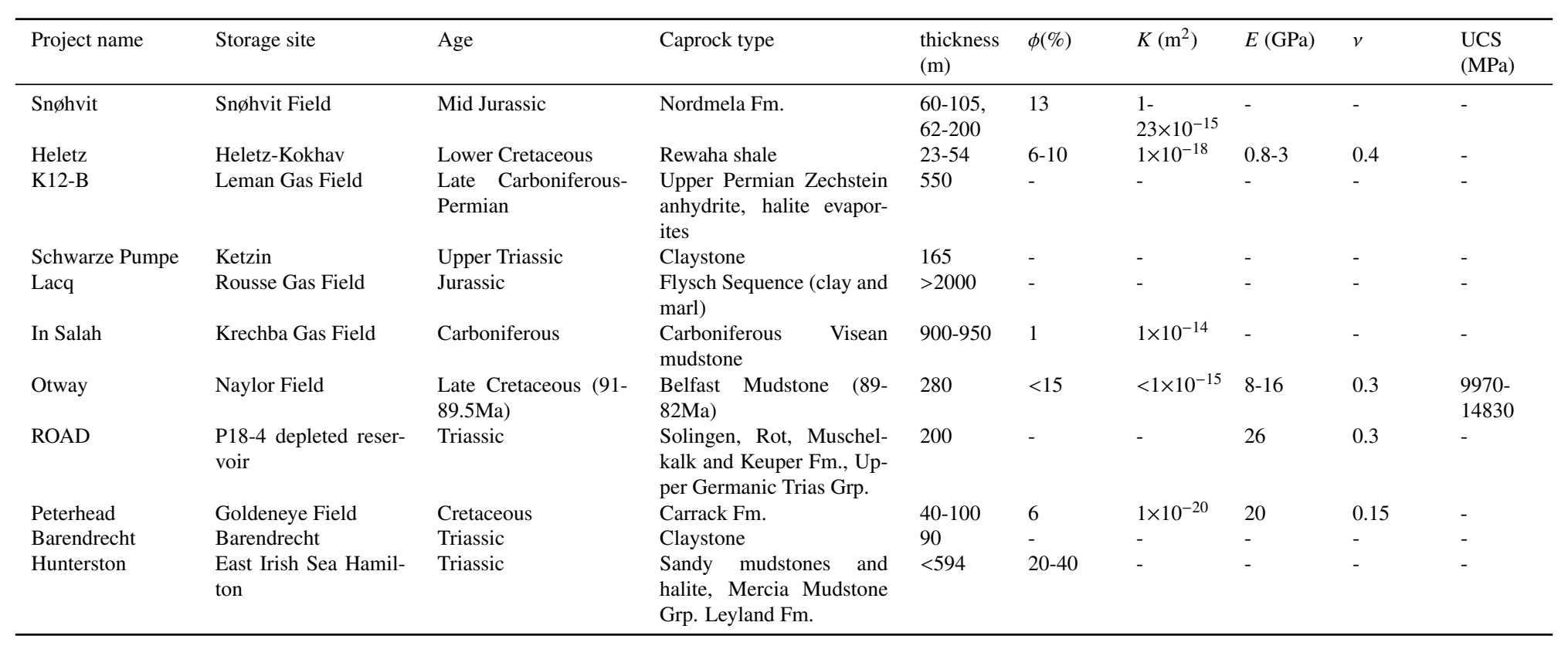

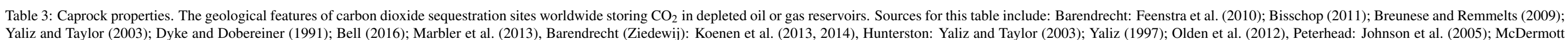

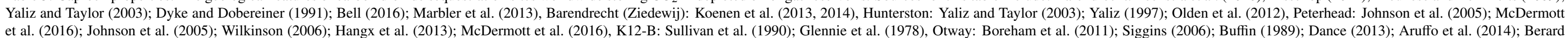

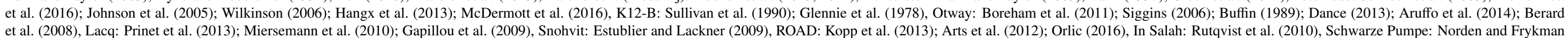
(2013); Norden et al. (2008); Klapperer et al. (2013b), Heletz: (Edlmann et al., 2016) 
Laboratory techniques. Several laboratory techniques are available for assessing transport properties of caprock materials, including steady-state, transient pulse-decay, and pore oscillation permeametry techniques. Recent efforts have compared these approaches and considered standardisation in detailed reviews (Busch and Mueller, 2011; Gensterblum et al., 2015; Sander et al., 2017). Concern relates to the trade-off between test accuracy and duration. Understanding the impact of the experimental approach is also of importance when parameterising numerical simulations. Clay-rich materials differ from reservoir rocks in that there is a significant coupling between chemical and mechanical state, and between hydraulic and mechanical state (Ewy, 2015; Lyu et al., 2018). Reduced salinity induces swelling that impacts porosity, permeability, and strength. Therefore, testing using a solution comparable to in situ pore fluid composition is desirable. Similarly, initial hydration of test samples must be conducted at in situ effective stress conditions to avoid sample swelling and consolidation (Ewy, 2015). Good sample preservation state is also key, as argillaceous materials are damaged by drying, resulting in erroneous data (Desbois et al., 2014). Several recent reviews have also considered a range of analytical methodologies for assessing pore-scale properties, which are often used to estimate transport behaviour (Bertier et al., 2016; Busch et al., 2017). As with flow testing, the influence of pore fluid and effective stress must be considered when transferring this data, as well as the potential for sample damage resulting from desiccation during analysis (Ewy, 2015). Caprock permeability data is not necessarily openly available for depleted storage sites, in part as a result of the scarcity of well-preserved core taken from offshore fields. However, there are studies examining hydraulic and gaseous flow behaviour for caprocks at Lacq (Tonnet et al., 2011) and Sleipner (Harrington et al., 2009), as well as for caprock that relates to prospective depleted sites in the East Irish Basin and Southern North Sea (Armitage et al., 2016; Harrington et al., 2018).

Shale caprocks. Direct assessment of geomechanical properties of shales is also often hampered by the shortage of well-preserved core and values are often estimated, without any calibration to laboratory data, using empiricallyderived correlations. However, recent evidence involving the collation of widely ranging laboratory mechanical datasets on shales has demonstrated a number of limitations to this approach in relation to the use of seismic velocity, porosity, and clay content data (Dewhurst et al., 2015). Where laboratory testing is performed, the choice of loading arrangement is key. In uniaxial deformation $\left(\sigma_{1}>>\sigma_{2}=\sigma_{3}=0\right)$, a cylindrical test sample is loaded axially under unconfined conditions, until failure. This is a simple and common mechanical test, allowing a rough comparison of strength between rocks. However, material behaviour may differ significantly in the presence of lithostatic pressure, particularly at higher effective stresses. This is considered in 'conventional' triaxial testing $\left(\sigma_{1}>\sigma_{2}=\sigma_{3}\right)$, where samples are loaded under a constant radial (or confining) stress, whilst axial load is increased. In both cases, samples are instrumented to quantify the evolution of deformation with time. More recently, a number of laboratories have developed 'true' triaxial cells $\left(\sigma_{1}>\sigma_{2}>\sigma_{3}\right)$, which allow deformation of cubic samples to be investigated in response to loading by three independently controlled stresses (Mortazavi and Atapour, 2018). For example, a recent study by Mortazavi and Atapour (2018) examined the evolution of minimum and maximum horizontal stresses in response to depletion and observed a sensitivity to the initial vertical stress applied.

Deformation of reservoir rocks. Deformation testing across a range of effective pressures allows the construction of yield and failure envelopes (e.g., Mohr-Coulomb, Mogi-Coulomb, Critical State) for a given rock, which can be used to predict material response under a chosen stress path. For example, the size and shape of the critical state yield envelope has been experimentally delineated for a wide range of sandstones (Cuss et al., 2003; Sheldon et al., 2006; Nguyen et al., 2014; Louis et al., 2017; Dobbs et al., 2018). In particular, sandstones compacted under deviatoric load (shear strain) have been found to have peak stress values approximately three times higher than samples with similar porosity compacted hydrostatically (volumetric strain) (Bedford et al., 2019). Fitting of models to this data allows the prediction of reservoir response for a given stress path scenario (Sheldon et al., 2006; Schutjens et al., 2004). This approach has been used in recent years to assess reservoir behaviour in response to depletion (Hol et al., 2018; Rathnaweera et al., 2018) and/or reinflation at several proposed CCS sites situated in depleted reservoirs (Orlic et al., 2011b; Hangx et al., 2013; Dobbs et al., 2018). Hangx et al. (2013) also investigated the effects of mineralogical reaction with $\mathrm{CO}_{2}$ upon the mechanical strength, for the Captain sandstone, in the context of reutilising the Goldeneye field. They demonstrated that the stress changes expected as a result of both depletion and reinflation were not sufficient to approach failure conditions for the reservoir. A similar approach was taken by Dobbs et al. (2018), who assessed the triaxial deformation behaviour of unreacted samples of Sherwood Sandstone, within the 
context of CCS storage in depleted UK Triassic reservoirs. Their findings also indicated that reservoir rock would not reach yield during drawdown or $\mathrm{CO}_{2}$, and also not during $\mathrm{CO}_{2}$ injection.

Deformation of caprocks. In contrast, similar studies are scarce for caprock materials, and data delineating the form of the yield surface are substantially lacking (Graham et al., 2019). For the Peterhead project, mechanical testing of caprock samples was not conducted due to core degradation (Shell, 2011). Instead, the friction angle was estimated based on a correlation with surface area measurements taken on shale cuttings (Shell, 2011). Similarly, cohesion values were estimated using a proprietary correlation with sonic log data. Mutschler et al. (2009) performed triaxial loading on claystone samples recovered from the injection well at the Ketzin pilot test. They focussed primarily on the impact of sample scale on viscosity index, which was found to be negligible at the sizes tested and also observed the transition from brittle to ductile deformation at higher effective pressures. Hangx et al. (2010a) conducted comprehensive deformation testing of dry and saturated anhydrite samples and delineated both failure and dilation envelopes for the material. They found no evidence that the presence of $\mathrm{CO}_{2}$ and pore fluid affected mechanical properties, on short timescales. Using the mechanical data derived, the authors considered depletion and injection scenarios for a hypothetical caprock, and found that integrity was not likely to be influenced by mechanical damage. Recent work has been conducted to examine the critical state envelope in several caprocks (Graham et al., 2019), considering both plastic and indurated samples with different compositions and diagenetic histories. Harrington et al. (2018) used mechanical data obtained from Mercia Mudstone Group samples to consider the impact of depletion- and reinflation-related stress changes and demonstrated the potential for yield in some, but not most, scenarios. Such an approach allows assessment of the type of yield behaviour, and they found that this was usually more likely to be compactive, and, hence, less likely to affect seal performance. Nevertheless, the impact of this deformation on faults and wellbores in the vicinity requires investigation by modelling on a larger scale (see Section 4).

Drained vs. undrained testing. As with transport testing, use of appropriate pore fluid composition and initial effective stress on hydration are key to ensure that no alteration occurs before geomechanical testing (Ewy, 2015; Lyu et al., 2018). A number of uncertainties must also be considered when parameterising numerical simulations with geomechanical test data for caprocks. In particular, the drainage condition used is particularly significant in low permeability materials (Islam and Skalle, 2013). In drained testing the pore pressure within the sample is maintained constant, whilst in undrained testing the pore fluid is isolated and pore pressures will tend to change during loading. The former approach is commonly used during testing of high permeability materials, but is experimentally more challenging in low permeability materials. The drainage condition can significantly impact the measured strength of the material and test findings should only be utilised under comparable conditions in numerical simulations.

Yield. An additional complication is uncertainty in determining the onset of yield. This is particularly important for shales, where inelastic deformation may begin substantially in advance of peak stress, resulting in only a brief elastic phase. A number of criteria may be used to assess the initiation of damage (Cuss et al., 2003; Nicksiar and Martin, 2012), including: (i) the deviation of the stress-strain curve from a linear trend, (ii) change in ultrasonic velocity, (iii) change in pore fluid volume, or (iv) onset of acoustic emissions (post-crack-closure). Nevertheless, these latter two methods are limited in their usefulness for shales, as (i) the necessity for quick testing means undrained conditions are often chosen (meaning pore fluid volume cannot be monitored) and (ii) the acoustic and mechanical properties of shale are such as to limit the effectiveness of acoustic emission detection. Recent work on samples including the Whitby Shale has indicated that analysis of ultrasonic attenuation may provide a useful indicator of the transition from elasticity to inelasticity (Barnhoorn et al., 2018). Understanding the criteria for the assessment of yield is important when utilising experimental data for numerical simulation. It is also important to discriminate between 'yield' envelopes, versus those constructed from peak stress data, since permeability may be enhanced before total caprock failure occurs. Nevertheless, with the exception of testing in anhydrite (Hangx et al., 2010b, 2011), there is minimal evidence that can quantify permeability enhancement in advance of failure, as a function of stress state in caprock materials.

Sample variability. Variability in rock samples impacts uncertainty in experimentally-determined mechanical properties. Sample variability can be the result of natural variability within the rock, and may also be the result of sample selection bias favouring the testing of more competent materials or bias caused by core recovery, likely to be higher 
in more competent sections of the borehole. Well-preserved caprock material is scarce and laboratory assessment of the impacts of lithological variability (e.g., from diagenesis) is rarely quantified, despite its influence on yield strength (Harrington et al., 2018). Handling of the (often substantial) anisotropy of caprocks is also vital (Ambrose and Zimmerman, 2015; Cheng et al., 2017), though it was historically less commonly quantified. Renewed interest in shale materials has resulted in a number of recent experimental studies examining the mechanical impact of this variation (Gao et al., 2015; Islam and Skalle, 2013; Rybacki et al., 2015; Bonnelye et al., 2017; Douma et al., 2019a,b).

Geomechanical characterisation aids in the selection of caprocks with properties that are favourable towards geomechanical stability and sealing during depletion and reinflation. It also provides the necessary parameterisation for reservoir modelling of sites with a significant stress history and small-scale validation of numerical approaches. Nevertheless, there are still limited quantitative data demonstrating the relationship between yield strength in shales and the influence of key controls (e.g., clay content, porosity, degree of cementation), as a function of stress state.

\section{Caprock integrity modelling studies of the depleted pilot sites}

Numerical models of $\mathrm{CO}_{2}$ injection, and its impact on reservoir and caprock properties, can be divided into three categories that balance computational cost with modelling accuracy: flow-only, iteratively-coupled, and fully-coupled models. Flow-based simulators include single-phase and multiphase flow with or without heat transfer, and solve the governing equations without taking into account mechanical coupling (Doughty and Pruess, 2004; Gasda et al., 2013). In iteratively coupled models, an independent geomechanical solver is linked to a flow simulator and the thermal, hydraulic, and mechanical problems are solved sequentially, feeding information into each other in a one-way or two-way manner (Rutqvist et al., 2010; Pan et al., 2014). In fully-coupled models, the set of coupled equations governing the flow in and deformation of reservoirs are formulated in a monolithic manner, and the problem is solved accounting for the physical processes simultaneously (Salimzadeh et al., 2018b). Computational and developmental time may be saved by using uncoupled or weakly coupled schemes at the cost of loss of accuracy; however, modelling monolithically coupled processes accurately is instrumental to modelling caprock failure, in particular if poroelastic or viscoelastic effects are considered. Table 4 summarises coupled computer codes that model thermo-hydro-mechanical processes with or without fractures and other discontinuities. These computer codes model a varied combination of deformation modes and mechanical models, including compressive in situ stress modelling, coupled elastic, elastoplastic and fracture mechanics, as well as coupled thermal and poroelastic effects. Reservoir modelling studies that focus on the discussed $\mathrm{CO}_{2}$ storage pilot sites (see Table 5), using various computer codes that implement geomechanics analysis (see Table 4), are discussed below. The listed studies are specific to depleted storage reservoirs, and simulations are specific to caprock integrity analysis in these scenarios. Approaches are validated independently against analytical and field data, highlighting the lack of a consistent set of validation benchmarks for coupled geomechanical simulations. In contrast to fluid-flow and fluid-flow in fractured media studies (Flemisch et al., 2018; Berre et al., 2019), benchmarks are lacking for fracture and fault propagation during thermo-hydro-mechanical deformation of subsurface reservoirs.

Overpressure and Fracture growth. Existing studies focus on fluid flow and caprock integrity by comparing overpressure with a limiting fracture pressure in addition to evaluating potential leakage pathways (e.g. Geel et al., 2006; der Meer et al., 2006; Shell, 2008; Eigestad et al., 2009; Estublier and Lackner, 2009; Hortle et al., 2009; Gapillou et al., 2009; Oldenburg et al., 2011; Pham et al., 2011; Jenkins et al., 2012b; MUSTANG, 2014a,b; Buscheck et al., 2016; Marshall et al., 2017). Implicit fracturing in the context of caprock integrity was investigated for the In Salah site (Gor et al., 2013a; Gor and Prevost, 2013; Gor et al., 2013b; Preisig and Prévost, 2011; Vilarrasa et al., 2015), for the Goldeneye field (Peterhead) (Akhurst et al., 2017; McDermott et al., 2016; Davison et al., 2012), for the Lacq project (Pourtoy et al., 2013), and for a generic depleted Dutch field (Orlic et al., 2011a). Explicit fracture growth for caprock integrity analysis was investigated for the Captain reservoir (Peterhead and Teesside Low Carbon) (Salimzadeh et al., 2018a) and the Heletz site (Paluszny et al., 2017). In particular, caprock integrity of the In Salah site has been studied extensively, and variations within the site models include using different numerical methods (finite differences vs. finite elements), different stress regimes (hypothetical normal fault regime vs. actual strike-slip stress conditions), different boundary conditions (with or without the underburden), different geometry scale, different temperature contrast (45 vs. 60 degrees), different injection duration and amount (570 tons/day for three years vs. 300 tons/day for thirty years), and different locations of the wells (middle vs at the base) (Vilarrasa et al., 2015; Preisig and Prévost, 2011). 


\begin{tabular}{|c|c|c|c|c|c|}
\hline Code & Reference & Numerical Method & Coupling & Discontinuity & Dimension \\
\hline TOUGH2/EGS & Xiong et al. (2013) & IFD & $\begin{array}{l}\text { THM (fully coupled)/ } \\
\text { THC (iterative) }\end{array}$ & $\begin{array}{l}\text { Fractured rock with em- } \\
\text { pirical correlation to frac- } \\
\text { ture aperture and fractured } \\
\text { rock properties. }\end{array}$ & $2 \mathrm{D}$ \\
\hline TOUGH2/FLAC & Rutqvist (2011) & IFD, FDM & $\begin{array}{l}\text { Iterative, Jacobian } \\
\text { (explicit) THM }\end{array}$ & $\begin{array}{l}\text { Fractured rock with empir- } \\
\text { ical correlation to fracture } \\
\text { aperture. }\end{array}$ & $3 \mathrm{D}$ \\
\hline TOUGH2/RDCA & Pan et al. (2014) & IFD, FEM & Iterative THM & $\begin{array}{l}\text { Pre-existing } \\
\text { ture/Faults }\end{array}$ & $2 \mathrm{D}$ \\
\hline COMSOL & $\begin{array}{l}\text { Selvadurai et al. } \\
(2015)\end{array}$ & FEM & Iterative THM & Fracture/Faults & $2 / 3 \mathrm{D}$ \\
\hline CODE_BRIGHT & $\begin{array}{l}\text { Zareidarmiyan et al. } \\
\text { (2018) }\end{array}$ & $\begin{array}{l}\text { FDM (temporal), } \\
\text { FEM (spatial) }\end{array}$ & Fully coupled THM & Fractures/Faults & $3 \mathrm{D}$ \\
\hline DYNAFLOW & $\begin{array}{l}\text { Prevost } \\
\text { Preisig and } \\
(2011)\end{array}$ & FEM & Fully coupled THM & - & $2 / 3 \mathrm{D}$ \\
\hline GPRS-PyLith & Jha and Juanes (2014) & Finite volume, FE & Iterative $\mathrm{HM}$ & Faults & $3 \mathrm{D}$ \\
\hline $\begin{array}{l}\text { T2STR (modified } \\
\text { TOUGH2) }\end{array}$ & Gosavi et al. (2005) & FDM, FEM & Fully coupled THM & - & $2 \mathrm{D}$ \\
\hline ICGT/CSMP & $\begin{array}{l}\text { Salimzadeh et al. } \\
(2018 \mathrm{a}, \mathrm{b})\end{array}$ & $\begin{array}{l}\text { FDM (temporal), } \\
\text { FEM (spatial) }\end{array}$ & Fully coupled THM & Faults/Fracture growth & $2 / 3 \mathrm{D}$ \\
\hline DIANA & Buijze et al. (2017) & FEM & $\begin{array}{l}\text { Sequentially coupled } \\
\text { to reservoir simulators }\end{array}$ & Faults/Fractures & $2 / 3 \mathrm{D}$ \\
\hline
\end{tabular}

Table 4: Numerical codes available in literature for THM modelling and fracture growth integration. IFD: Integral Finite Difference Method (Narasimhan and Witherspoon, 1976), FEM: Finite Element Method, FDM: Finite Difference Method, DEM: Discrete Element Method, THM: Thermo-Hydro-Mechanical, THC:Thermo-Hydro-Chemical, TOUGH2 (Pruess et.al., 1999). 


\begin{tabular}{|c|c|c|c|c|c|c|c|c|}
\hline Project name & Reference & $2 / 3 \mathrm{D}$ & Constitutive Model & Scale $(\mathrm{km})$ & Tool & $\begin{array}{l}\text { Time } \\
(\mathrm{yr})\end{array}$ & Fractures, Faults & Findings \\
\hline Snøhvit & $\begin{array}{l}\text { Chiaramonte } \\
\text { et al. (2011) }\end{array}$ & $3 \mathrm{D}$ & $\begin{array}{l}\text { one phase fully coupled HM, MC fail- } \\
\text { ure criterion }\end{array}$ & $9 \times 6 \times 2.1$ & $\begin{array}{l}\text { Geocentric (FE) with em- } \\
\text { bedded discontinuities }\end{array}$ & 30 & faults & $\begin{array}{l}\text { Maximum horizontal stress orientation, friction coef- } \\
\text { ficient of faults and poroelastic effects important for } \\
\text { fault reactivation. Hydrofracturing may occur before } \\
\text { major fault reactivation }\end{array}$ \\
\hline Heletz & $\begin{array}{l}\text { Paluszny et al. } \\
\text { (2017) }\end{array}$ & $3 \mathrm{D}$ & $\begin{array}{l}\text { LE, disk-shaped interaction integral to } \\
\text { compute the three stress intensity fac- } \\
\text { tors, THM fully coupled, Augmented } \\
\text { Lagrangian method for fracture wall } \\
\text { friction }\end{array}$ & $0.5 \times 0.4 \times 0.5$ & ICGT, CSMP++ (FEM) & 1 & $\begin{array}{l}\text { explicit fracture growth, } \\
\text { SIFs, faults }\end{array}$ & $\begin{array}{l}\text { Fracture propagation in the reservoir mostly down- } \\
\text { wards due to cold plume, caprock integrity not af- } \\
\text { fected }\end{array}$ \\
\hline Lacq & $\begin{array}{l}\text { Pourtoy et al. } \\
\text { (2013) \& Total } \\
(2015)\end{array}$ & $1 / 3 \mathrm{D}$ & $\begin{array}{l}\text { One way } \mathrm{HM} / \mathrm{LE} / \text { poroelasticity / } \\
\text { MC failure criterion }\end{array}$ & $4 \times 4 \times 5$ & 1D MEM, 3D FEM & $41+5$ & $\begin{array}{l}\text { Fault reactivation, implicit } \\
\text { fracture propagation }\end{array}$ & $\mathrm{CO}_{2}$ injection minimal impact on caprock integrity \\
\hline In Salah & Gor et al. (2013a) & 2D & $\begin{array}{l}\text { brine - } \mathrm{CO}_{2} \text { mixture, fully coupled } \\
\mathrm{THM} / \mathrm{MC} \text { nonlinear (shear) }\end{array}$ & $5 \times 1.82$ & DynaFlow FE code & 12 & $\begin{array}{l}\text { implicit fracture initiation } \\
\text { and propagation }\end{array}$ & $\begin{array}{l}\text { Initial stresses important, rock thermal expansion can } \\
\text { lead to large changes in stresses due to pore pres- } \\
\text { sure build up, resulting in tensile stress regimes in the } \\
\text { caprock but also shear failure }\end{array}$ \\
\hline In Salah & $\begin{array}{l}\text { Preisig and } \\
\text { Prévost (2011) }\end{array}$ & $2 \mathrm{D}$ & $\begin{array}{l}\text { brine- } \mathrm{CO}_{2} \text { mixture, fully-coupled } \\
\text { two-phase } \\
\text { (shear) }\end{array}$ & $5 \times 1.82$ & DynaFlow FE code & 3 & implicit fracture initiation & $\begin{array}{l}\text { Increased pore fluid pressure due to poromechanical } \\
\text { effects unlikely to affect caprock integrity, whereas } \\
\text { with thermomechanics tensile stresses can develop in } \\
\text { the caprock, inducing growth or leakage }\end{array}$ \\
\hline Otway & $\begin{array}{l}\text { Aruffo and Henk } \\
\text { (2014) }\end{array}$ & $3 \mathrm{D}$ & $\begin{array}{l}\text { one way HM / MC failure criterion / } \\
\text { linear and non-linear }\end{array}$ & $4 \times 4 \times 2.8$ & $\begin{array}{l}\text { FEM stress / ECLIPSE } \\
\text { flow / VISAGE }\end{array}$ & - & fault reactivation / faults & Faults not likely to reactivate \\
\hline Otway & $\begin{array}{l}\text { Aruffo et al. } \\
\text { (2014) }\end{array}$ & $3 \mathrm{D}$ & $\begin{array}{l}\text { one way HM / Byerlee (1978)-type } \\
\text { fault friction / MC failure criterion }\end{array}$ & $12 \times 12 \times 4.5$ & ECLIPSE flow / VISAGE & 8 & fault reactivation & $\begin{array}{l}\text { Numerical models yield lower critical pore fluid pres- } \\
\text { sure for reactivation than analytical models }\end{array}$ \\
\hline ROAD & $\begin{array}{l}\text { Peters et al. } \\
(2013)\end{array}$ - & $2 / 3 \mathrm{D}$ & multi-phase & $\begin{array}{ll}\mathrm{r}=0.7 \quad(2 \mathrm{D}) \\
/ & \mathrm{r}=6 \\
\mathrm{z}=2.5(3 \mathrm{D})\end{array}$ & $\begin{array}{l}\text { TOUGH2, ECO2M, DI- } \\
\text { ANA }\end{array}$ & 5 & fracture growth & At the actual depth no thermal fracturing was induced \\
\hline ROAD & $\begin{array}{l}\text { Orlic et al. } \\
(2011 \mathrm{~b}) \& \text { Orlic } \\
\text { et al. (2011a) }\end{array}$ & 2D & $\begin{array}{l}\mathrm{MC}(\text { res/cap), no cohesion for faults, } \\
\mu_{f}=0.6\end{array}$ & $10 \times 6$ & DIANA / PFC2D & 50,000 & fault re-activation & $\begin{array}{l}\text { Top seal leass affected by poromechanical effects. No } \\
\text { faults fail }\end{array}$ \\
\hline $\begin{array}{l}\text { Peterhead } \\
\text { Goldeneye }\end{array}$ & $\begin{array}{l}\text { Salimzadeh et al. } \\
\text { (2018a) }\end{array}$ & 3D & LE / THM & $10 \times 6 \times 4$ & ICGT, CSMP++ (FEM) & $10+160$ & $\begin{array}{l}\text { fracture growth, SIF's, } \\
4 \text { faults included for } \\
\text { re-activation }\end{array}$ & $\begin{array}{l}\text { Mode I growth not observed, partial mode II fracture } \\
\text { growth at interface of reservoir/caprock }\end{array}$ \\
\hline Peterhead & $\begin{array}{l}\text { Akhurst et al. } \\
(2017)\end{array}$ & $2 / 3 \mathrm{D}$ & Fully coupled THM multi-physics, LE & $163 \times 84 \times 5$ & Open Geosys & 35 & $\begin{array}{l}\text { tensile failure / rock frac- } \\
\text { turing / reactivation of } \\
\text { faults }\end{array}$ & $\begin{array}{l}\text { Interaction due to pressure, not due to temperature } \\
\text { contrast }\end{array}$ \\
\hline Peterhead & $\begin{array}{l}\text { McDermott et al. } \\
\text { (2016) }\end{array}$ & $2 / 3 \mathrm{D}$ & $\begin{array}{l}\text { Fully coupled THM, LE homogeneous } \\
\text { isotropic materials }\end{array}$ & $130 \times 20 \times 4$ & Open Geosys & 30 & $\begin{array}{l}\text { tensile failure/rock fractur- } \\
\text { ing/reactivation of faults }\end{array}$ & $\begin{array}{l}\text { Stress bridging can increase horizontal stress and lead } \\
\text { to enhanced stability of the caprock }\end{array}$ \\
\hline $\begin{array}{l}\text { Barendrecht } \\
\text { \& K12-B }\end{array}$ & $\begin{array}{l}\text { Orlic et al. } \\
(2011 \mathrm{a}, \mathrm{b})\end{array}$ & 2D & $\begin{array}{l}\text { MC (reservoir/caprock), no cohesion } \\
\text { for faults, } \mu_{f}=0.6\end{array}$ & $10 \times 6$ & DIANA, PFC2D & 50,000 & fault re-activation & $\begin{array}{l}\text { Top seal less affected by poromechanical effects. No } \\
\text { faults fail }\end{array}$ \\
\hline
\end{tabular}

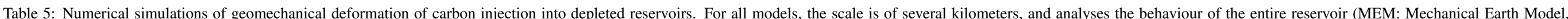

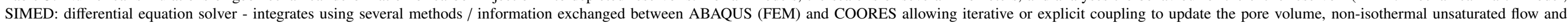
transport (NUFT)). 
Orlic et al. (2011a) showed the importance of site characterisation and numerical modelling to predict the maximum allowable overpressures to ensure caprock integrity. Mechanical stability studies of the caprock for Goldeneye (Shell, 2011) and Lacq-Rousse (Pourtoy et al., 2013), showed that injection pressures do not exceed the minimum total principal stress, nor are they expected to exceed initial gas pressure before depletion. McDermott et al. (2016) found a much smaller extent of the thermal $\mathrm{CO}_{2}$ plume compared to the injection-induced fluid overpressure in the long-term. They found that reservoir rock contraction due to cold $\mathrm{CO}_{2}$ injection results in a stabilising arching effect of the horizontal stresses in the caprock. Akhurst et al. (2017) studied interaction effects of consecutive injections of $\mathrm{CO}_{2}$, and found no interaction due to temperature contrast. Conversely, interaction due to overpressure was noted, despite the distance between the sites being on the order of tens of kilometres. This agrees with the findings of McDermott et al. (2016).

Gor et al. (2013a) and Gor and Prevost (2013) estimated fracture propagation analytically based on numerically computed results. They found that thermally-induced stresses can lead to tensile regimes developing in the caprock, which may lead to fracturing, while shear failure of both the reservoir and caprock rocks can also be aided by a large temperature difference. Gor and Prevost (2013), who accounted only for poromechanical effects (HM) in their simulations, analytically predicted rapid fracture propagation during injection. Conversely, Preisig and Prévost (2011) found that the injection-induced fluid overpressure alone would not be sufficient to affect the caprock mechanical stability in terms of tensile failure. When accounting for thermal effects, though, tensile stresses in the caprock were found to develop, and fracture flow could potentially extend the fracture growth outside the thermally affected zone (Preisig and Prévost, 2011). No shear failure was predicted for the caprock. Vilarrasa et al. (2015) also showed that thermal effects due to cold $\mathrm{CO}_{2}$ injection can be significant in a zone of a few tens of metres close to the interface with the storage rock; however, due to the caprock thickness $(900 \mathrm{~m})$ in In Salah, this should not influence the overall sealing performance. Tensile failure was predicted when the minimum horizontal stress was based on White et al. (2014), highlighting the importance of accurate representation of the initial stress regime. Davison et al. (2012) accounted for THM effects, and found the caprock integrity not to be at risk.

Studies that model fracture growth explicitly are far fewer, as compared to implicit and analytical studies. Paluszny et al. (2017) studied the Heletz field using a finite element numerical model that combines THM full coupling with fracture growth, by computing the three modes of stress intensity factors (i.e. mode I: tensile, mode II: sliding and mode III: tearing). Results showed that fracture growth takes place in a downward direction, not largely influencing the caprock. Salimzadeh et al. (2018a), using the same numerical model, predicted minimal mode II fracture growth at the interface of the reservoir and caprock rocks when modelling Goldeneye with the implication that caprock breach is unlikely. Conversely, Peters et al. (2013), in the ROAD project, used iterative coupling between TOUGH2 and DIANA to calculate the size of the fractures to model the increased permeability, and found no thermal fracturing when the reservoir was modelled at its actual depth, agreeing with the results of Vandeweijer et al. (2011).

With regard to shear failure of the caprock, Orlic (2016) carried out geomechanical analyses for the ROAD project (the P18-2 depleted reservoir was modelled rather than the P18-4), and showed that stress changes were larger at the end of depletion than during injection, but no shear failure of the caprock was predicted at the end of depletion. He also showed that the area mostly affected during depletion and injection is more limited, compared to injection in saline aquifers.

Fracture Permeability. Tensile fracturing of the caprock does not necessarily imply a pathway to flow (Paluszny and Matthäi, 2010). Thus, predicted growth does not necessarily translate to containment loss, as only when the effective permeability is enhanced is $\mathrm{CO}_{2}$ leakage likely to take place. Numerical models that can explicitly account for fracturing can replicate this process, using variable permeability models (based on geomechanically-computed apertures as opposed to uniform fracture apertures) as a function of fracture growth and in situ stresses (Lang et al., 2018). Additionally, as aforementioned, different studies employ different forms of thermo-hydro-mechanical coupling (i.e. full, one-way or iterative). Preisig and Prévost (2011) have shown that the type of coupling used is of utmost importance to the accuracy of the predictions. The time-integration scheme when transient conditions are considered (e.g. consolidation), and the size of the time step chosen, are also of fundamental importance for the accuracy of the numerical solution (Potts and Zdravković, 1999). Iding and Ringrose (2010) accounted for fractures to calculate effective permeabilities for In Salah, however, their analyses focussed only on fluid flow calculations. The dimensionality of the problem is important in accounting for geometry effects, as 3D predictions can substantially depart from 2D predictions of growth and permeability (Lang et al., 2014). Geomechanical studies of 2D and 3D fracture growth found that 
the predicted permeability of a geomechanical system may be lower if mechanically realistic apertures are considered (Paluszny and Matthäi, 2010; Thomas, 2019). In fact, in interacting fractures, apertures may be suppressed by the shadow zone of nearby fractures, further reducing the permeability of the system (Salimzadeh et al., 2017; Thomas et al., 2017).

Fault reactivation and induced seismicity. Fault reactivation and its impact on sealing performance has been studied for In Salah (Vilarrasa et al., 2015), Snøhvit (Chiaramonte et al., 2011), for generic depleted Dutch fields (Orlic et al., 2011b), for Otway (Aruffo and Henk, 2014; Aruffo et al., 2014; Krawczyk et al., 2015), for North Sea reservoirs relevant to Peterhead and Hunterston (Chadwick et al., 2015; Akhurst et al., 2017; McDermott et al., 2016; Shell, 2011), and for Lacq Rousse (Pourtoy et al., 2013; Total, 2015). Vilarrasa et al. (2015) and Orlic et al. (2011b) found the fault shear failure to be more critical than the tensile failure of the caprock, while Chiaramonte et al. (2011) computed the maximum injection-induced overpressure for fault shear slip for different stress regimes at Snøvit. Vilarrasa et al. (2015) suggested that during cold injection in a normal fault stress regime, stress redistribution was unlikely to induce fault shear slip, as the thermal strains have the effect of tightening the caprock and preventing leakage. Akhurst et al. (2017) and McDermott et al. (2016) also accounted for fault reactivation to compute the maximum injection overpressure. Aruffo et al. (2014) showed that the numerically computed maximum overpressure for shear slip is substantially smaller than that computed analytically, while the studies of Krawczyk et al. (2015) showed that faults are likely leakage paths. Aruffo and Henk (2014) predicted no fault reactivation for the conditions modelled, similar to the predictions of Chadwick et al. (2015) for Peterhead and Pourtoy et al. (2013) and Total (2015) for Lacq as long as the post-injection pressure remains below the initial gas pressure.

Inversion modelling and ground surface displacement. Inverse modelling to match the observed ground surface displacement magnitudes and patterns has also been conducted to understand the opening of fractured zones and faults at depth. Examples of these are (Shi et al., 2013; Rinaldi and Rutqvist, 2017; Bissell et al., 2011; Gemmer et al., 2012; Fokker et al., 2011; Morris et al., 2011; Rutqvist, 2011), and Vasco et al. (2010), who focussed on In Salah. Modelling of a fractured zone, often extending through the caprock, was required to match the observed surface deformation. $\mathrm{Li}$ and Laloui (2016) carried out a "blind prediction" of the surface uplift observed next to the injection well KB501 at In Salah during the 4.5 years of cold $\mathrm{CO}_{2}$ injection. The results of a $2 \mathrm{D}$ thermo-hydro-mechanical analysis with full coupling and multiphase fluid flow predicted a high potential for shear failure of both the reservoir and cap rocks. This was found to be a result of an increased deviatoric stress from the initial anisotropic stress state, due to a decrease in the in situ effective stress from the combined effect of pressure increase and temperature drop.

Thermal stresses. Thermal stresses can develop tensile regimes in the caprock (e.g. Gor et al., 2013a; Preisig and Prévost, 2011), which may lead to fracture growth and damage conducive to an increase in permeability. Thermal stresses depend on the temperature difference, as well as the bulk modulus and the coefficient of volumetric thermal expansion of the rock matrix (Zimmerman, 2000). Variability in the values of these factors can, therefore, play a major role in these non-converging results. Different sites will obviously have different mechanical (both stiffness and strength), hydraulic and thermal parameters of the various rocks, explaining, at least partly, the difference in the results. The geometry and thicknesses of the various strata can also play a key role, as explained by Vilarrasa et al. (2015) for In Salah. Peters et al. (2013) and Vilarrasa et al. (2015) highlighted the importance of the in situ stresses, as a smaller overburden (i.e., shallower depth) and lower minimum horizontal stress can enhance the temperature contrast effect.

Vilarrasa et al. (2015) also emphasise the importance of the orientation of the injection well for caprock integrity, as well as the significance of thermal stresses when $\mathrm{CO}_{2}$ is injected at a much lower temperature than the in situ temperature. Despite this, several studies only account for poro-mechanical effects (e.g. Gor et al., 2013b; Orlic et al., $2011 \mathrm{~b}$ ), although injection of liquid $\mathrm{CO}_{2}$, which is commonly at a lower temperature than that in the reservoir, has become more common (Vilarrasa et al., 2013; Vilarrasa and Laloui, 2015).

\section{Geomechanical studies and public perception of the depleted pilot sites}

Public perception studies specific to the considered pilot sites are scarce, more so in the context of the actual geomechanics of these sites. Pilot studies and their findings serve to inform experts and policy makers who may 
have an impact on regulatory frameworks, and can inform public acceptance through successful public engagement at project site level (Xenias and Whitmarsh, 2018). While public support for CCS is generally lower than expert stakeholder acceptance (Huijts et al., 2007; Shackley et al., 2007; Oltra et al., 2010), both groups consider CCS to be a partial solution to climate change. In general, storage of $\mathrm{CO}_{2}$ in depleted reservoirs engages with local communities that have experience with other subsurface industries (Sacuta et al., 2017), and can directly benefit from continued usage of these sites.

There are a number of studies related to the Barendrecht site in the Netherlands, a case in which social perceptions in the form of protests stalled and halted development (Xenias and Whitmarsh, 2018). Public responses to $\mathrm{CO}_{2}$ storage in this and other European sites have cited concerns about the potential impact of carbon storage on "health, the environment and the local community in general", referring to the potential effects of local leakage of $\mathrm{CO}_{2}$ into an urban area (Oltra et al., 2012). In Barendrecht, in addition to lack of support from politicians (Brunsting et al., 2011), the main concerns of local residents related to the potential negative impacts of $\mathrm{CO}_{2}$ leakage on public health and safety (Oltra et al., 2012), and consequences for the value of their properties (Terwel et al., 2012). In Finland, CCS suffered from poor and negative attention from the media after 2009 (Kojo and Innola, 2017), and was categorised as an alternative to renewables (Teir et al., 2011), as opposed to being considered as a complementary carbon-offsetting technology. In Hunterston, concerns from the public that eventually led to cancellation of the project, included fear of uncontrolled leakage and long-term migration, and the possible effect on marine ecosystems, as well as induced seismicity (Mabon et al., 2014, 2015). These factors are strongly related to the assessment of the caprock integrity of the site, which for the Hunterston site was scarcely reported in the literature.

In contrast, a number of geomechanical studies that investigate caprock integrity scenarios have been conducted for the on-hold projects Peterhead (Akhurst et al., 2017; McDermott et al., 2016; Salimzadeh et al., 2018a) and ROAD (Peters et al., 2013; Orlic et al., 2011b), as well as for concluded projects, including Otway, In Salah, Lacq, Schwarze Pumpe, and K12-B. The latter have a number of accompanying geomechanical studies focused on caprock integrity (Preisig and Prévost, 2011; Chiaramonte et al., 2011; Gor et al., 2013a; Pourtoy et al., 2013; Aruffo and Henk, 2014; Aruffo et al., 2014; Vilarrasa et al., 2015). For Snøhvit, geomechanical studies included understanding fault reactivation (Chiaramonte et al., 2011), geomechanically-driven changes to permeability during injection (Hansen et al., 2013), and the study of in situ 3D fracture network properties and their influence on fault permeability (Wennberg et al., 2008). The ongoing Heletz pilot $\mathrm{CO}_{2}$ injection site in Israel was supported by a number of large EU-funded projects (PANACEA, TRUST, and MUSTANG) which financed numerical injection experiments focussed primarily on quantifying capillary/residual trapping (Niemi et al., 2016), but also on mechanical studies that examined caprock stability during cold injection (Paluszny et al., 2017). In this case, no public opposition was apparent and the project was supported by local regulating authorities.

Most of these sites considered leakage and seismicity, and in many cases, operations relied on extensive surface and subsurface-based monitoring to minimise these risks. Providing information about CCS does not always allay fears or change attitudes (Upham and Roberts, 2011a,b; Wallquist et al., 2011; Brunsting et al., 2013a; Braun et al., 2018). However, it is notable that both the way in which CCS information is framed (van Knippenberg and Daamen, 1996; Whitmarsh et al., 2019) and audience characteristics (e.g., knowledge, values, cultural world views) influence public views on the technology (Yang et al., 2016; Brunsting et al., 2013b; Hope and Jones, 2014; Howell et al., 2014; Krause et al., 2013; Warren et al., 2014; Karimi et al., 2016) It is the case, however, for most of the completed projects that geomechanical studies contributed to the quantification of caprock integrity during storage, and in many cases were instrumental in providing interpretations during monitoring. Such studies could provide a useful tool for building confidence in CCS technology and as a public engagement tool.

In the general study of social perception of CCS, there is a disparity in public perception according to whether attitudes are studied at the level of the general public, or specific communities that are likely to be affected by CCS (Midden and Huijts, 2009; Huijts et al., 2007). The strength of this disparity may well differ for depleted storage sites, where previous interaction with the hydrocarbon industry is often present, although there is limited research assessing this. As with other energy developments (e.g., nuclear, wind, geothermal, wave), different public and communities will respond differently to CCS in general, as opposed to specific proposed sites; "public acceptance of CCS in the global sphere does not necessarily translate to local support for a CCS storage site" (Poumadère et al., 2011; Krause et al., 2013; Braun, 2017). For the general public, factors such as values, beliefs, trust, and education are likely to predict CCS support, while for proposed/actual communities affected, familiarity with the industry, operator trust, place identity, and perceived costs and benefits are likely to be more important (Desbarats et al., 2010). These 
are only some of the factors that may influence public perceptions, and wider, more integrated social and technical research is needed to address public acceptance (Mabon et al., 2013). For communities close to depleted sites it is likely that several of these latter factors are likely to differ significantly to those in regions less familiar with offshore industry. Nevertheless, public response at both Barendrecht and Hunterston demonstrate the potential for concerns around storage integrity at depleted sites. More generally, CCS faces sustainability concerns and geological concerns, including the perceived increased risk of induced seismicity and leakage (Seigo et al., 2014b), both of which can be tied to the geomechanical performance of the seal that traps the carbon in place. Understanding the geomechanics of the seal traps is a necessary step, which if translated and communicated appropriately will address some of the concerns associated with geological storage.

\section{Final Remarks}

Advantages of carrying out CCS at depleted reservoirs include a history of previous containment, often substantial geological and geophysical characterisation, and the potential to incorporate pre-existing infrastructure into new schemes. They differ from previously unused sites due to previous anthropogenic involvement, which may include factors such as a history of geomechanical perturbation and the presence of multiple boreholes. Studies that relate to depleted pilot sites for CCS have been collated and examined in relation to three key aspects associated with assessment and perception of containment at these sites:

1. Characterisation of storage site materials provides the fundamental data and understanding necessary to constrain performance assessment and parameterise predictive simulations.

- Geomechanical data used for parameterising numerical simulations is substantially less common for caprock materials.

- Care needs to be taken when selecting parameters from the experimental and analytical literature and transferring to appropriate conditions.

- Heterogeneity remains a topic for further work, particularly for caprock materials, where a lack of test material limits testing for calibration and/or verification of values from proprietary relationships.

- These factors will contribute to the overall degree of certainty in performance assessment through simulation.

2. Caprock integrity modelling studies are instrumental to understanding the effects of storage site materials, geological structure, and injection protocols on the long term storage of $\mathrm{CO}_{2}$.

- Numerical studies of the depleted sites consider overpressure, fracture growth, fault reactivation, ground surface displacement, and the effect of thermal stresses. These have been developed with a number of independently validated simulators capable of capturing mechanical, flow, thermal, and geochemical processes that ensue during injection into depleted reservoirs.

- The numerical studies of the sites are primarily focused on understanding the conditions leading to the potential onset of leakage and induced seismicity, rather that on the quantification of leakage rates or seismicity development over longer periods of time. These two factors feed into some financial liability models that monetise the risk of caprock integrity breach associated with CCS sites.

- Numerical studies study a variation of rock materials, and in situ and injection conditions, often assuming that rock layers are homogeneous and in many cases geometrically simplified.

- Findings suggest a series of geomechanical benchmarks quantifying leakage rates for specific scenarios is necessary. These benchmarks should be tied to field-based validations, and to critical societal and operator concerns such as potential leakage rates over short and long periods of time.

- These numerical models improve our understanding of mechanical changes that occur during injection and storage both in general, and for specific reservoirs, and contribute to building confidence in the capacity to store carbon while seeking to minimise both leakage and seismicity.

3. Public concern over leakage risks has been a contributing factor in the cancellation of some projects. 
- Providing information about CCS does not always allay fears or change attitudes.

- CCS faces sustainability and geological concerns, including perceived increased risk of induced seismicity and leakage

- These factors can be tied to the geomechanical performance of the storage seal and this should be considered by experts and regulators during the development of a public engagement strategy.

Examining studies from these three perspectives, it is clear that geomechanical effects, relating to both leakage and induced seismicity, are strongly linked to both the real and perceived risks of CCS at depleted storage sites. The geomechanics literature tends to emphasise the evaluation of induced seismicity, thermal stresses, and injection pressure constraints. Examining perception and risk analyses alongside pilot site-specific studies suggests the need for the geomechanics community not only to perform binary caprock integrity studies (e.g. will a given site leak or not leak), but to perform long-term quantifications of leakage, estimating leakage rates, and analysing potential 'domino' effects of leaks. Careful quantification and assessment of aspects such as the role of heterogeneity, localisation of flow, and the permeability evolution of faults and fractures/damage, will improve certainty around storage site evolution and containment. When combined with careful monitoring to confirm behaviour, such an approach will contribute to reduced technical and financial risks, contribute to a sound public engagement approach, and facilitate the successful development of CCS projects in depleted hydrocarbon reservoirs.

\section{Acknowledgements}

This work was supported by the Engineering and Physical Sciences Research Council (EPSRC) EP/K036025/1. Co-funding for the study was provided by the BGS Geosphere Containment research project, Imperial College, and Cardiff University. This paper is published with the permission of the Executive Director, British Geological Survey (NERC). Adriana Paluszny thanks the Royal Society for partially funding this research through fellowship UF160443. The authors thank the Royal Society for partially funding this research through fellowship UF160443. The authors also thank MSc Tariq El-Hassan and MSc Salma Zaki for contributions to early versions of this work.

\section{References}

Akhurst, M., Mallows, T., Pearce, J., Mackay, E., 2017. Assessing Interactions between Multiple Geological $\mathrm{CO}_{2}$ Storage Sites to Optimize Capacity in Regionally Extensive Storage Sandstones. Energy Procedia 114 (Supplement C), 4571-4582.

Amaro, T., Bertocci, I., Queiros, A., Rastelli, E., Borgersen, G., Brkljacic, M., Nunes, J., Sorensen, K., Danovaro, R., Widdicombe, S., 2018. Effects of sub-seabed $\mathrm{CO}_{2}$ leakage: Short- and medium-term responses of benthic macrofaunal assemblages. Marine Pollution Bulletin 128 , $519-526$.

Ambrose, J., Zimmerman, R., 2015. Failure of Anisotropic Shales under Triaxial Compression and Extension. In: International Society for Rock Mechanics and Rock Engineering. Paper ISRM-13CONGRESS-2015-344.

Armannsson, H., 2017. Carbon dioxide emissions fro Icelandic geothermal areas. Procedia Earth and Planetary Science 17, 104-107, 15th WaterRock Interaction International Symposium, WRI-15.

Armitage, P. J., Worden, R. H., Faulkner, D. R., Butcher, A. R., Espie, A. A., 2016. Permeability of the mercia mudstone: suitability as caprock to carbon capture and storage sites. Geofluids $16(1), 26-42$.

Arning, K., van Heek, J. O., Linzenich, A., Kaetelhoen, A., Sternberg, A., Bardow, A., Ziefle, M., 2019. Same or different? Insights on public perception and acceptance of carbon capture and storage or utilization in Germany. Energy Policy 125, 235 - 249.

Arts, R. J., Vandeweijer, V. P., Hofstee, C., Pluymaekers, M. P. D., Loeve, D., Kopp, A., Plug, W.-J., 2012. The feasibility of con storage in the depleted p18-4 gas field offshore the netherlands (the road project). International Journal of Greenhouse Gas Control 11 (supplement), S10-S20.

Aruffo, C., Henk, A., 2014. Fault Stability Assessment of CO2CRC Otway Project, Australia. A Geomechanical Approach. In: 76th EAGE Conference and Exhibition. Amsterdam, the Netherlands, pp. 1-5.

Aruffo, C. M., Rodriguez-Herrera, A., Tenthorey, E., Krzikalla, F., Minton, J., Henk, A., 2014. Geomechanical modelling to assess fault integrity at the $\mathrm{CO}_{2} \mathrm{CRC}$ Otway Project, Australia. Australian Journal of Earth Sciences 61 (7), 987-1001.

Ashworth, P., Einsiedel, E., Howell, R., Brunsting, S., Boughen, N., Boyd, A., Shackley, S., Bree, B. V., Jeanneret, T., Stenner, K., Medlock, J., Mabon, L., Feenstra, C. Y., Hekkenberg, M., 2013. Public Preferences to CCS: How does it Change Across Countries? Energy Procedia 37, 7410 - 7418, gHGT-11 Proceedings of the 11th International Conference on Greenhouse Gas Control Technologies, 18-22 November 2012, Kyoto, Japan.

Ashworth, P., Romanach, T. J. L., Ranasinghe, N., 2014. Understanding Stakeholder Attitudes to CCS in Victoria, Australia. Energy Procedia 63, 6982 - 6990, 12th International Conference on Greenhouse Gas Control Technologies, GHGT-12.

Ashworth, P., Wade, S., Reiner, D., Liang, X., 2015. Developments in public communications on CCS. International Journal of Greenhouse Gas Control 40, 449 - 458, special Issue commemorating the 10th year anniversary of the publication of the Intergovernmental Panel on Climate Change Special Report on $\mathrm{CO}_{2}$ Capture and Storage. 
Barnhoorn, A., Verheij, J., Frehner, M., Zhubayev, A., Houben, M., 2018. Experimental identification of the transition from elasticity to inelasticity from ultrasonic attenuation analyses. Geophysics 83 (4), MR221-MR229.

Barrett, S., 2017. Gasunie plans first 1 MW P2G hydrogen plant in Netherlands. Fuel Cells Bulletin 2017 (8), 14.

Bedford, J. D., Faulkner, D. R., Wheeler, J., Leclère, H., 2019. High-resolution mapping of yield curve shape and evolution for high-porosity sandstone. Journal of Geophysical Research: Solid Earth 124 (6), 5450-5468.

Bell, F., 2016. Fundamentals of Engineering Geology. Elsevier.

Berard, T., Sinha, B. K., van Ruth, P., Dance, T., John, Z., Tan, C. P., 2008. Stress Estimation at the Otway $\mathrm{CO}_{2}$ Storage Site, Australia. In: SPE Asia Pacific Oil and Gas Conference and Exhibition, 20-22 October, Perth, Australia.

Berre, I., Doster, F., Keilegavlen, E., Oct 2019. Flow in fractured porous media: A review of conceptual models and discretization approaches. Transport in Porous Media 130 (1), 215-236. URL https: //doi.org/10.1007/s11242-018-1171-6

Bertier, P., Schweinar, K., Stanjek, H., Ghanizadeh, A., Clarkson, C. R., Busch, A., Kampman, N., Prinz, D., Amann-Hildenbrand, A., Krooss, B. M., Pipich, V., 01 2016. On the Use and Abuse of N2 Physisorption for the Characterization of the Pore Structure of Shales. In: Filling the Gaps - from Microscopic Pore Structures to Transport Properties in Shales. Clay Minerals Society.

Bickle, M. J., 2009. Geological carbon storage. Nature Geoscience 2, 815-818.

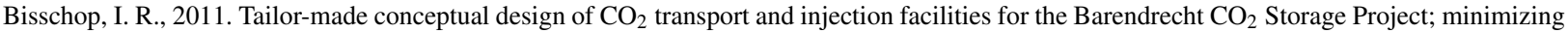
risk and optimising lifecycle value. Energy Procedia 4, 2369-2376.

Bissell, R. C., Vasco, D. W., Atbi, M., Hamdani, M., Okwelegbe, M., Goldwater, M. H., 2011. A full field simulation of the in Salah gas production and $\mathrm{CO}_{2}$ storage project using a coupled geo-mechanical and thermal fluid flow simulator. Energy Procedia 4 (Supplement C), $3290-3297$.

Bonafin, J., Pietra, C., Bonzanini, A., Bombarda, P., 2019. CO2 emissions from geothermal power plants: evaluation of technical solutions for CO2 reinjection. In: European Geothermal Congress 2019. Den Haag, The Netherlands, 11-14 June.

Bonnelye, A., Schubnel, A., David, C., Henry, P., Guglielmi, Y., Gout, C., Fauchille, A.-L., Dick, P., 2017. Strength anisotropy of shales deformed under uppermost crustal conditions. Journal of Geophysical Research: Solid Earth 122 (1), 110-129.

Boothroyd, I., Almond, S., Qassim, S., Worrall, F., Davies, R., 2016. Fugitive emissions of methane from abandoned, decommissioned oil and gas wells. Science of The Total Environment 547, $461-469$.

Boreham, C., Underschultz, J., Stalker, L., Kirste, D., Freifeld, B., Jenkins, C., Ennis-King, J., 2011. Monitoring of CO 2 storage in a depleted natural gas reservoir: Gas geochemistry from the $\mathrm{CO}_{2} \mathrm{CRC}$ Otway Project, Australia. International Journal of Greenhouse Gas Control 5 (4), 1039 - 1054.

Bouzalakos, S., Mercedes, M., 2010. 1 - overview of carbon dioxide ( $\left.\mathrm{co}_{2}\right)$ capture and storage technology. In: Maroto-Valer, M. M. (Ed.), Developments and Innovation in Carbon Dioxide $\left(\mathrm{CO}_{2}\right)$ Capture and Storage Technology. Vol. 1 of Woodhead Publishing Series in Energy. Woodhead Publishing, pp. $1-24$

Braun, C., 2017. Not in My Backyard: CCS Sites and Public Perception of CCS. Risk Analysis 37 (12), 2264-2275.

Braun, C., Merk, C., Pönitzsch, G., Rehdanz, K., Schmidt, U., 2018. Public perception of climate engineering and carbon capture and storage in Germany: survey evidence. Climate Policy 18 (4), 471-484.

Breunese, J. N., Remmelts, G., 2009. Inventory of potential locations for demonstration project co 2 -storage. TNO Report TNO-034-UT-200902024, 1-34.

Brownsort, P. A., Scott, V., Haszeldine, R. S., 2016. Reducing costs of carbon capture and storage by shared reuse of existing pipeline-Case study of a $\mathrm{CO}_{2}$ capture cluster for industry and power in Scotland. International Journal of Greenhouse Gas Control 52, 130 - 138.

Brunsting, S., de Best-Waldhober, M., Brouwer, A., Riesch, H., Reiner, D., 2013a. Communicating CCS: Effects of Text-only and Text-and-visual Depictions of $\mathrm{CO}_{2}$ Storage on Risk Perceptions and Attitudes. Energy Procedia 37, 7318 - 7326, gHGT-11 Proceedings of the 11th International Conference on Greenhouse Gas Control Technologies, 18-22 November 2012, Kyoto, Japan.

Brunsting, S., de Best-Waldhober, M., Feenstra, C. Y., Mikunda, T., 2011. Stakeholder participation practices and onshore CCS: Lessons from the dutch CCS case Barendrecht. Energy Procedia 4, 6376 - 6383, 10th International Conference on Greenhouse Gas Control Technologies.

Brunsting, S., de Best-Waldhober, M., Terwel, B. W., 2013b. 'I Reject your Reality and Substitute my Own!' Why More Knowledge about CO 2 Storage Hardly Improves Public Attitudes. Energy Procedia 37, 7419 - 7427, gHGT-11 Proceedings of the 11th International Conference on Greenhouse Gas Control Technologies, 18-22 November 2012, Kyoto, Japan.

Brunsting, S., Mastop, J., Kaiser, M., Zimmer, R., Shackley, S., Mabon, L., Howell, R., 2015. CCS Acceptability: Social Site Characterization and Advancing Awareness at Prospective Storage Sites in Poland and Scotland. Oil Gas Sci. Technol. - Rev. IFP Energies nouvelles 70 (4), 767-784.

Buffin, A. J., 1989. Waarre sandstone development within the port cambell embayment. The APPEA Journal 29(1), $299-311$.

Buhr, K., Wibeck, V., 2014. Communication approaches for carbon capture and storage: Underlying assumptions of limited versus extensive public engagement. Energy Research \& Social Science 3, 5 - 12.

Buijze, L., van den Bogert, P. A., Wassing, B. B., Orlic, B., ten Veen, J., 2017. Fault reactivation mechanisms and dynamic rupture modelling of depletion-induced seismic events in a Rotliegend gas reservoir. Netherlands Journal of Geosciences 96 (5), s131-s148.

Burgess, J., Chilvers, J., 2006. Upping the ante: a conceptual framework for exploring participatory technology assessments. Science and Public Policy 33, 713-728.

Busch, A., Mueller, N., 2011. Determining $\mathrm{CO}_{2}$ /brine relative permeability and capillary threshold pressures for reservoir rocks and caprocks: Recommendations for development of standard laboratory protocols. Energy Procedia 4, 6053 - 6060, 10th International Conference on Greenhouse Gas Control Technologies.

Busch, A., Schweinar, K., Kampman, N., Coorn, A., Pipich, V., Feoktystov, A., Leu, L., Amann-Hildenbrand, A., Bertier, P., 2017. Determining the porosity of mudrocks using methodological pluralism. Geological Society, London, Special Publications 454.

Buscheck, T. A., White, J. A., Carroll, S. A., Bielicki, J. M., Aines, R. D., 2016. Managing geologic CO 2 storage with pre-injection brine production: a strategy evaluated with a model of CO 2 injection at Snøhvit. Energy \& Environmental Science 9 (4), 1504-1512.

Carbon Capture and Sequestration Technologies at MIT, 2016. Carbon capture and sequestration project database. Data retrieved from https://sequestration.mit.edu/tools/projects/index.html. 
Carley, S. R., Krause, R. M., Warren, D. C., Rupp, J. A., Graham, J. D., 2012. Early public impressions of terrestrial carbon capture and storage in a coal-intensive state. Environmental Science \& Technology 46 (13), 7086-7093.

Chadwick, A., Holloway, S., Hannis, S., Rochelle, C., Williams, J., Mackay, E., Ford, J., Pickup, G., Somerville, J., Tohidi, B., 2015. External review of the storage plan for the Peterhead carbon capture and storage project. Tech. rep., British Geological Survey.

Chadwick, R., Noy, D., Arts, R., Eiken, O., 2009. Latest time-lapse seismic data from sleipner yield new insights into co2 plume development. Energy Procedia 1 (1), 2103 - 2110, greenhouse Gas Control Technologies 9.

Cheng, C., Li, X., Qian, H., 2017. Anisotropic Failure Strength of Shale with Increasing Confinement: Behaviors, Factors and Mechanism. Materials (Basel) 10, 1310.

Chiaramonte, L., Johnson, S., White, J. A., 2011. Preliminary Geomechanical Analysis of $\mathrm{CO}_{2}$ Injection At Snøhvit, Norway. In: 45th US Rock MEchanics / Geomechanics Symposium. American Rock Mechanics Association, San Francisco, CA.

Chrysostomidis, I., Perumalpillai, S., Bohm, M., Crombie, M., Beynon, E., Lee, A., 2013. Co2 capture project's CCS stakeholder issues review and analysis. Energy Procedia 37, 7832 - 7839, gHGT-11 Proceedings of the 11th International Conference on Greenhouse Gas Control Technologies, 18-22 November 2012, Kyoto, Japan.

Coulthurst, A., Taylor, S., Baddeley, A., 2011. The East Irish Sea CCS Cluster: A Conceptual Design -Technical Report. Tech. rep., Eunomia Research and Consulting.

Cuss, R., Rutter, E., Holloway, R., 2003. The application of critical state soil mechanics to the mechanical behaviour of porous sandstones. International Journal of Rock Mechanics and Mining Sciences 40 (6), 847 - 862.

Damen, K., Faber, R., Gnutek, R., van Dijk, H., Trapp, C., Valenz, L., 2014. Performance and Modelling of the Pre-combustion Capture Pilot Plant at the Buggenum IGCC. Energy Procedia 63, 6207 - 6214, 12th International Conference on Greenhouse Gas Control Technologies, GHGT-12.

Dance, T., 2013. Assessment and geological characterisation of the $\mathrm{co}_{2} \mathrm{crc}$ otway project $\mathrm{co}_{2}$ storage demonstration site: From prefeasibility to injection. Marine and Petroleum Geology 46, $251-269$.

Dance, T., Spencer, L., Xu, J.-Q., 2009. Geological characterisation of the Otway project pilot site: What a difference a well makes. Energy Procedia 1 (1), 2871 - 2878, greenhouse Gas Control Technologies 9.

Davison, J., de Vries, S., Ita, J., Acevedo, L., Shinde, A., Fokker, P., Wentinck, R., 2012. CCS in the Goldeneye Field, UK - A Geomechanical Assessment of Containment. In: 3rd EAGE $\mathrm{CO}_{2}$ Geological Storage Workshop.

de Best-Waldhober, M., Paukovic, M., Brunsting, S., Daamen, D., 2011. Awareness, knowledge, beliefs, and opinions regarding CCS of the dutch general public before and after information. Energy Procedia 4, 6292 - 6299, 10th International Conference on Greenhouse Gas Control Technologies.

der Meer, L. G. H., Kreft, E., Geel, C., Hartman, J., 2005. K12-B a Test Site for $\mathrm{CO}_{2}$ Storage and Enhanced Gas Recovery (SPE94128). In: 67th Europec/EAGE Annual Conference \& Exhibition. Madrid, Spain.

der Meer, L. G. H., Kreft, E., Geel, C. R., D’Hoore, D., Hartman, J., 2006. Enhanced gas recovery testing in the K12-B reservoir by CO 2 injection, a reservoir engineering study. In: 8th International Conference on Greenhouse Gas Control Technologies. pp. 19-22.

Desbarats, J., Upham, P., Riesch, H., Reiner, D., Brunsting, S., de Best-Waldhober, M., Dütschke, E., Oltra, C., Sala, R., McLachlan, C., 2010. Review of the public participation practices for CCS and non-CCS projects in Europe. Tech. rep., Amsterdam.

Desbois, G., Urai, J. L., Hemes, S., Brassinnes, S., Craen, M. D., Sillen, X., 2014. Nanometer-scale pore fluid distribution and drying damage in preserved clay cores from Belgian clay formations inferred by BIB-cryo-SEM. Engineering Geology $179,117-131$.

Dewhurst, D. N., Sarout, J., Piane, C. D., Siggins, A. F., Raven, M. D., 2015. Empirical strength prediction for preserved shales. Marine and Petroleum Geology 67, $512-525$.

Dobbs, M. R., Cuss, R. J., Ougier-Simonin, A., Parkes, D., Graham, C. C., 2018. Yield envelope assessment as a preliminary screening tool to determine carbon capture and storage viability in depleted southern north-sea hydrocarbon reservoirs. International Journal of Rock Mechanics and Mining Sciences 102, $15-27$.

Doughty, C., Pruess, K., 2004. Modeling Supercritical Carbon Dioxide Injection in Heterogeneous Porous Media. Vadose Zone J 3, $837-847$.

Douma, L., Dautriat, J., Sarout, J., Dewhurst, D., Barnhoorn, A., 2019a. Impact of the Degree of Saturation on the Mechanical Behaviour of the Whitby Mudstone. In: Sixth EAGE Shale Workshop.

Douma, L., Dautriat, J., Sarout, J., Dewhurst, D., Barnhoorn, A., 2019b. The Elastic Anisotropy of the Whitby Mudstone Formation at Varying Water Saturations. In: Sixth EAGE Shale Workshop.

Duetschke, E., 2011. What drives local public acceptance-comparing two cases from germany. Energy Procedia 4, $6234-6240$.

Duetschke, E., Wohlfarth, K., Hoeller, S., Viebahn, P., Schumann, D., Pietzner, K., 2016. Differences in the public perception of CCS in germany depending on $\mathrm{CO}_{2}$ source, transport option and storage location. International Journal of Greenhouse Gas Control 53, 149 - 159

Dyke, C. G., Dobereiner, L., 1991. Evaluating the strength and deformability of sandstones. Quarterly Journal of Engineering Geology and Hydrogeology 24 (1), 123-134.

Edlmann, K., Niemi, A., Bensabat, J., Haszeldine, R., McDermott, C., 2016. Mineralogical properties of the caprock and reservoir sandstone of the Heletz field scale experimental $\mathrm{CO}_{2}$ injection site, Israel; and their initial sensitivity to $\mathrm{CO}_{2}$ injection. International Journal of Greenhouse Gas Control 48, $94-104$.

Eigestad, G. T., Dahle, H. K., Hellevang, B., Riis, F., Johansen, W. T., Øian, E., aug 2009. Geological modeling and simulation of CO 2 injection in the Johansen formation. Computational Geosciences 13 (4), 435.

Elhami, E., Ask, M., Mattsson, H., 2016. Physical- and geomechanical properties of a drill core sample from 1.6km depth at the Heletz site in Israel: Some implications for reservoir rock and CO2 storage. International Journal of Greenhouse Gas Control 48, $84-93$, characterization of formation properties for geological storage of $\mathrm{CO} 2$ - Experiences from the Heletz test injection site and other example sites from the EU project MUSTANG.

Estublier, A., Lackner, A. S., 2009. Long-term simulation of the Snøhvit $\mathrm{CO}_{2}$ storage. Energy Procedia 1, 3221-3228.

Ewy, R., 2019. Claystone Porosity and Mechanical Behavior vs. Geologic Burial Stress. In: Sixth EAGE Shale Workshop.

Ewy, R. T., 2015. Shale/claystone response to air and liquid exposure, and implications for handling, sampling and testing. International Journal of Rock Mechanics and Mining Sciences 80, $388-401$. URL http://www.sciencedirect.com/science/article/pii/S1365160915300666 
Feenstra, C. F. J., Mikunda, T., Brunsting, S., 2010. What happened in Barendrecht?! Case study on the planned onshore carbon dioxide storage in Barendrecht, the Netherlands. ECN Policy Studies ECN-E-10-057, 44.

Figueres, C., Quéré, C. L., Peters, G. P., Whiteman, G., Mahindra, A., et al., D. G., 2018. Emissions are still rising: ramp up the cuts. Nature 564, 27-30.

Flemisch, B., Berre, I., Boon, W., Fumagalli, A., Schwenck, N., Scotti, A., Stefansson, I., Tatomir, A., Jan 2018. Benchmarks for single-phase flow in fractured porous media. Advances in Water Resources 111, 239-258. URL http://dx.doi.org/10.1016/j.advwatres.2017.10.036

Fokker, O., Orlic, B., van der Meer, L., Geel, C., 2011. Geomechanical Modeling of Surface Uplift around Well KB-502 at the In Salah CO 2 Storage Site. In: 73rd EAGE Conference and Exhibition incorporating SPE EUROPEC 2011.

Fridriksson, T., Mateos, A., Audinet, P., Orucu, Y., 2011. Greenhouse gases from geothermal power production. Tech. rep., The World Bank, energy Sector Management Assistance Program. Technical Report 009/16.

Gal, F., Pokryszka, Z., Labat, N., Michel, K., Lafortune, S., Marblé, A., 2019. Soil-gas concentrations and flux monitoring at the lacq-rousse co2-geological storage pilot site (french pyrenean foreland): From pre-injection to post-injection. Applied Sciences 9 (4).

Gao, Q., Tao, J., Hu, J., Yu, X. B., 2015. Laboratory study on the mechanical behaviors of an anisotropic shale rock. Journal of Rock Mechanics and Geotechnical Engineering 7 (2), $213-219$

Gao, Y., 2013. Reservoir Characterization of Snøhvit Field, Norwegian Barents Sea. Master's thesis, Oslo University, OSlo, Norway.

Gapillou, C., Thibeau, S., Mouronval, G., Lescanne, M., 2009. Building a geocellular model of the sedimentary column at Rousse $\mathrm{CO}_{2}$ geological storage site (Aquitaine, France) as a tool to evaluate a theorical maximum injection pressure. Energy Procedia 1 (1), $2937-2944$.

Gasda, S. E., Nilsen, H. M., Dahle, H. K., 2013. Impact of structural heterogeneity on upscaled models for large-scale $\mathrm{CO}_{2}$ migration and trapping in saline aquifers. Advances in Water Resources 62, 520 - 532, computational Methods in Geologic $\mathrm{CO}_{2} \mathrm{Sequestration}_{\text {. }}$

Geel, C., Arts, R., van Eijs, R., Kreft, E., Hartman, J., D’Hoore, D., 2006. Geological characterisation of the nearly depleted K12-B gas field, offshore the Netherlands. In: International Symposium on Site Characterization for $\mathrm{CO}_{2}$ Geological Storage. pp. 124-126.

Gemmer, L., Hansen, O., Iding, M., Leary, S., Ringrose, P., 2012. Geomechanical response to $\mathrm{CO}_{2}$ injection at Krechba, In salah, Algeria. First Break 30 (2), 79-84.

Gensterblum, Y., Ghanizadeh, A., Cuss, R., Amann-Hildenbrand, A., Krooss, B., Clarkson, C., Harrington, J., Zoback, M., 2015. Gas transport and storage capacity in shale gas reservoirs: A review. part a: Transport processes. Journal of Unconventional Oil and Gas Resources 12 , 87-122.

Glennie, K. W., Mudd, G. C., Nagtegaal, P. J. C., 1978. Depositional environment and diagenesis of Permian Rotliegendes sandstones in Leman Bank and Sole Pit areas of the UK Southern North Sea. Journal of the Geological Society of London 135, $25-34$.

Gomersall, S., Murphy, S., Robertson, H., Hartley, C., et al., A. J., 2018. Co 2 transportation and storage business models. Tech. Rep. 10251BEISRep-01-04, Pale Blue Dot Energy.

Gor, G. Y., Elliot, T. R., Prévost, J. H., 2013a. Effects of thermal stresses on caprock integrity during $\mathrm{CO}_{2}$ storage. International Journal of Greenhouse Gas Control 12, 300-309.

Gor, G. Y., Prevost, J., jan 2013. Effect of $\mathrm{CO}_{2}$ Injection Temperature on Caprock Stability. Energy Procedia 37, 3727-3732.

Gor, G. Y., Stone, H. A., Prévost, J. H., oct 2013b. Fracture Propagation Driven by Fluid Outflow from a Low-Permeability Aquifer. Transport in Porous Media 100 (1), 69-82.

Gough, C., Cunningham, R., Mander, S., 2018. Understanding key elements in establishing a social license for CCS: An empirical approach. International Journal of Greenhouse Gas Control 68, 16-25.

Gough, C., O'Keefe, L., Mander, S., 2014. Public perceptions of $\mathrm{co}_{2}$ transportation in pipelines. Energy Policy $70,106-114$.

Graham, C., Harrington, J., Cuss, R., Daniels, K., 2019. Yield characteristics of caprocks: a critical state mechanics approach. In: Sixth EAGE Shale Workshop.

Ha-Duong, M., Gaultier, M., deGuillebon, B., 2011. Social aspects of Total's Lacq $\mathrm{CO}_{2}$ capture, transport and storage pilot project. Energy Procedia 4, 6263 - 6272, 10th International Conference on Greenhouse Gas Control Technologies.

Hangx, S., Spiers, C., Peach, C., 2011. The mechanical behavior of anhydrite and the effect of deformation on permeability development-Implications for caprock integrity during geological storage of CO2. Energy Procedia 4, $5358-5363$.

Hangx, S., van der Linden, A., Marcelis, F., Bauer, A., 2013. The effect of $\mathrm{co}_{2}$ on the mechanical properties of the captain sandstone: Geological storage of $\mathrm{CO}_{2}$ at the goldeneye field (uk). International Journal of Greenhouse Gas Control 19, 609-619.

Hangx, S. J. T., Spiers, C. J., Peach, C. J., 2010a. Mechanical behavior of anhydrite caprock and implications for CO2 sealing capacity. Journal of Geophysical Research: Solid Earth 115 (B7)

Hangx, S. J. T., Spiers, C. J., Peach, C. J., 2010b. The effect of deformation on permeability development in anhydrite and implications for caprock integrity during geological storage of CO2. Geofluids 10 (3), 369-387.

Hansen, O., Gilding, D., Nazarian, B., Osdal, B., Ringrose, P., Kristoffersen, J.-B., Eiken, O., Hansen, H., 2013. Snøhvit: The history of injecting and storing $1 \mathrm{mt} \mathrm{co} 2$ in the fluvial tubåen fm. Energy Procedia 37, 3565 - 3573, gHGT-11 Proceedings of the 11th International Conference on Greenhouse Gas Control Technologies, 18-22 November 2012, Kyoto, Japan.

Harrington, J., Graham, C., Tamayo-Mas, E., Parkes, D., 2018. Stress controls on transport properties of the Mercia Mudstone Group: Importance for hydrocarbon depletion and $\mathrm{CO}_{2}$ injection. Marine and Petroleum Geology 93, $391-408$.

Harrington, J. F., Noy, D. J., Horseman, S. T., Birchall, D. J., Chadwick, R. A., 2009. Laboratory Study of Gas and Water Flow in the Nordland Shale, Sleipner, North Sea.

Herzog, H. J., 2016. Carbon capture and sequestration project database. Massachusetts Institute of Technology https://sequestration.mit.edu/.

Hol, S., van der Linden, A., Bierman, S., Marcelis, F., Makurat, A., 2018. Rock physical controls on production-induced compaction in the Groningen Field. Nature Scientific Reports 8, 7156.

Hope, A. L., Jones, C. R., 2014. The impact of religious faith on attitudes to environmental issues and carbon capture and storage (ccs) technologies: A mixed methods study. Technology in Society $38,48-59$.

Hortle, A., de Caritat, P., Stalvies, C., Jenkins, C., 2011. Groundwater monitoring at the Otway project site, Australia. Energy Procedia 4, 5495 5503.

Hortle, A. H., Xu, J., Dance, T., 2009. Hydrodynamic interpretation of the Waarre Fm Aquifer in the onshore Otway Basin: Implications for the 
CO2CRC Otway Project. Energy Procedia 1 (1), 2895-2902.

Howell, R., Shackley, S., Mabon, L., Ashworth, P., Jeanneret, T., 2014. Engaging the public with low-carbon energy technologies: Results from a scottish large group process. Energy Policy 66, $496-506$.

Huijts, N. M., Midden, C. J., Meijnders, A. L., 2007. Social acceptance of carbon dioxide storage. Energy Policy 35 (5), 2780 - 2789.

Iding, M., Ringrose, P., 2010. Evaluating the impact of fractures on the performance of the In Salah $\mathrm{CO}_{2}$ storage site. International Journal of Greenhouse Gas Control 4 (2), 242-248.

IEA, 2013. Technology Roadmap. Carbon Capture and Storage.

URL http://www.iea.org/publications/freepublications/publication/CCS Roadmap.pdf

IPCC, Climate Change, 2014. Mitigation of Climate Change. Contribution of Working Group III to the Fifth Assessment Report of the Intergovernmental Panel on Climate Change. Cambridge University Press, Cambridge, UK and New York, NY.

Islam, M. A., Skalle, P., Nov 2013. An experimental investigation of shale mechanical properties through drained and undrained test mechanisms. Rock Mechanics and Rock Engineering 46 (6), 1391-1413.

Iso-Tryykäri, M., Rauramo, J., Pekkanen, E., 2011. FINNCAP - Meri-Pori CCS demonstration project. Energy Procedia 4, 5599 - 5606, 10th International Conference on Greenhouse Gas Control Technologies.

Jenkins, C. R., Cook, P. J., Ennis-King, J., Undershultz, J., Boreham, C., Dance, T., de Caritat, P., Etheridge, D. M., Freifeld, B. M., Hortle, A., Kirste, D., Paterson, L., Pevzner, R., Schacht, U., Sharma, S., Stalker, L., Urosevic, M., 2012a. Safe storage and effective monitoring of $\mathrm{CO}_{2}$ in depleted gas fields. Proceedings of the National Academy of Sciences 109 (2), E35-E41.

Jenkins, C. R., Cook, P. J., Ennis-King, J., Undershultz, J., Boreham, C., Dance, T., de Caritat, P., Etheridge, D. M., Freifeld, B. M., Hortle, A., Kirste, D., Paterson, L., Pevzner, R., Schacht, U., Sharma, S., Stalker, L., Urosevic, M., 2012b. Safe storage and effective monitoring of $\mathrm{CO}_{2}$ in depleted gas fields. Proceedings of the National Academy of Sciences 109 (2), E35-E41.

Jha, B., Juanes, R., 2014. Coupled multiphase flow and poromechanics: A computational model of pore pressure effects on fault slip and earthquake triggering. Water Resources Research 50 (5), 3776-3808

URL https://agupubs . onlinelibrary.wiley.com/doi/abs/10.1002/2013WR015175

Joffe, D., Livermore, S., et al., M. H., 2018. Hydrogen in a low-carbon economy. Tech. rep., Committee on Climate Change.

Johnson, H., Leslie, A. B., Wilson, C. K., Andrews, I. J., Cooper, R. M., 2005. Middle Jurassic, Upper Jurassic and Lower Cretaceous of the UK Central and Northern North Sea. British Geological Survey Research Report RR/03/001, 42pp.

Kapetaki, Z., Hetland, J., Guenan, T. L., Mikunda, T., Scowcroft, J., 2017. Highlights and Lessons from the EU CCS Demonstration Project Network. Energy Procedia 114, 5562 - 5569, 13th International Conference on Greenhouse Gas Control Technologies, GHGT-13, 14-18 November 2016, Lausanne, Switzerland.

Karimi, F., Toikka, A., 2018. General public reactions to carbon capture and storage: Does culture matter? International Journal of Greenhouse Gas Control 70, 193 - 201.

Karimi, F., Toikka, A., Hukkinen, J. I., 2016. Comparative socio-cultural analysis of risk perception of carbon capture and storage in the european union. Energy Research \& Social Science 21, $114-122$.

Karimnezhad, M., Jalalifar, H., Kamari, M., 2014. Investigation of caprock integrity for $\mathrm{CO}_{2}$ sequestration in an oil reservoir using a numerical method. Journal of Natural Gas Science and Engineering 21, 1127 - 1137.

Kaya, E., Zarrouk, S. J., 2017. Reinjection of greenhouse gases into geothermal reservoirs. International Journal of Greenhouse Gas Control 67 , $111-129$.

Kim, K., Kemeny, J., jan 2009. Effect of Thermal Shock And Rapid Unloading On Mechanical Rock Properties. In: 43rd US Rock Mechanics Symposium \& 4th US-Canada Rock Mechanics Symposium. American Rock Mechanics Association.

Klapperer, S., Moeck, I., Lempp, C., 2013a. Impact of Petrographical Attributes on Geomechanics in a Sandstone Reservoir for $\mathrm{CO}_{2} \mathrm{Storage}$ Ketzin, Germany. In: 75th EAGE Conference \& Exhibition incorporating SPE EUROPEC 2013.

Klapperer, S., Moeck, I. S., Lempp, C., 2013b. Impact of Petrographical Attributes on Geomechanics in a Sandstone Reservoir for $\mathrm{CO}_{2} \mathrm{Storage} \mathrm{-}^{-}$ Ketzin, Germany. In: 75th EAGE Conference and Exhibition incorporating SPE EUROPEC 2013. Amsterdam, the Netherlands.

Koenen, M., Wasch, L. J., van Zalinge, M. E., Nelskamp, S., 2013. Werkendam, the dutch natural analogue for $\mathrm{co}_{2}$ storage - long-term mineral reactions. Energy Procedia 37, 3452-3460.

Koenen, M., Wasch, L. J., Waldmann, S., van der Gijp, S., 2014. Observed $\mathrm{co}_{2}$-induced reactivity in werkendam gas field, the dutch storage analogue. Energy Procedia 63, 2985-2993.

Kojo, M., Innola, E., 2017. Carbon Capture and Storage in the Finnish Print Media. Risk, Hazards \& Crisis in Public Policy 8 (2), 113-146.

Kopp, A., Ros, M., Jonker, T., Wevers, J.-P., Gittins, C., Plug, W.-J., 2013. Aspects of the storage permit application for $\mathrm{Co}_{2}$ storage in the depleted gas field offshore the netherlands. Energy Procedia 37, 6287-6294.

Krause, R. M., Carley, S. R., Warren, D. C., Rupp, J. A., Graham, J. D., 2013. "not in (or under) my backyard": Geographic proximity and public acceptance of carbon capture and storage facilities. Risk Analysis 34 (3), 529-540.

Krawczyk, C., Tanner, D., Ziesch, J., Beilecke, T., Henk, A., 2015. Deformation Prediction in the Otway Basin - A Seismo-mechanical Workflow for Sub-/seismic Fault Detection. In: The Third Sustainable Earth Sciences Conference and Exhibition.

Krüger, M., Jones, D., Frerichs, J., Oppermann, B. I., West, J., Coombs, P., Green, K., Barlow, T., Lister, R., Shaw, R., Strutt, M., Möller, I., 2011. Effects of elevated $\mathrm{CO}_{2}$ concentrations on the vegetation and microbial populations at a terrestrial $\mathrm{CO}_{2}$ vent at Laacher See, Germany. International Journal of Greenhouse Gas Control 5 (4), 1093 - 1098.

Kuijper, I. M., 2011. Public acceptance challenges for onshore $\mathrm{co}_{2}$ storage in barendrecht. Energy Procedia 4, 6226-6233.

Lang, P. S., Paluszny, A., Nejati, M., Zimmerman, R. W., 2018. Relationship Between the Orientation of Maximum Permeability and Intermediate Principal Stress in Fractured Rocks. Water Resources Research 54 (11), 8734-8755.

Lang, P. S., Paluszny, A., Zimmerman, R. W., 2014. Permeability tensor of three-dimensional fractured porous rock and a comparison to trace map predictions. Journal of Geophysical Research: Solid Earth 119 (8), 6288-6307.

Le Quéré, C., Andrew, R. M., Friedlingstein, P., Sitch, S., Hauck, J., Pongratz, J., Pickers, P. A., Korsbakken, J. I., Peters, G. P., Canadell, J. G., Arneth, A., Arora, V. K., Barbero, L., Bastos, A., Bopp, L., Chevallier, F., Chini, L. P., Ciais, P., Doney, S. C., Gkritzalis, T., Goll, D. S., Harris, I., Haverd, V., Hoffman, F. M., Hoppema, M., Houghton, R. A., Hurtt, G., Ilyina, T., Jain, A. K., Johannessen, T., Jones, C. D., Kato, 
E., Keeling, R. F., Goldewijk, K. K., Landschützer, P., Lefèvre, N., Lienert, S., Liu, Z., Lombardozzi, D., Metzl, N., Munro, D. R., Nabel, J. E. M. S., Nakaoka, S.-I., Neill, C., Olsen, A., Ono, T., Patra, P., Peregon, A., Peters, W., Peylin, P., Pfeil, B., Pierrot, D., Poulter, B., Rehder, G., Resplandy, L., Robertson, E., Rocher, M., Rödenbeck, C., Schuster, U., Schwinger, J., Séférian, R., Skjelvan, I., Steinhoff, T., Sutton, A., Tans, P. P., Tian, H., Tilbrook, B., Tubiello, F. N., van der Laan-Luijkx, I. T., van der Werf, G. R., Viovy, N., Walker, A. P., Wiltshire, A. J., Wright, R., Zaehle, S., Zheng, B., 2018. Global Carbon Budget 2018. Earth System Science Data 10 (4), 2141-2194.

Lee, Y., Lee, G., An, J., Kim, K., Ahmed, U., Lee, C.-J., Han, C., 2018. Quantitative risk assessment of offshore carbon dioxide injection system considering seismic effects. International Journal of Greenhouse Gas Control 77, 1 - 13.

Lena, E. D., Spinelli, M., Gatti, M., Scaccabarozzi, R., Campanari, S., Consonni, S., Cinti, G., Romano, M. C., 2019. Techno-economic analysis of calcium looping processes for low $\mathrm{CO}_{2}$ emission cement plants. International Journal of Greenhouse Gas Control 82, $244-260$.

Lescanne, M., Hy-Billiot, J., Aimard, N., Prinet, C., 2011. The site monitoring of the Lacq industrial CCS reference project. Energy Procedia 4, 3518 - 3525, 10th International Conference on Greenhouse Gas Control Technologies.

Li, C., Laloui, L., 2016. Coupled multiphase thermo-hydro-mechanical analysis of supercritical $\mathrm{CO}_{2}$ injection: Benchmark for the In Salah surface uplift problem. International Journal of Greenhouse Gas Control 51, 394-408.

Li, C., Laloui, L., 2017. Impact of material properties on caprock stability in $\mathrm{CO}_{2}$ geological storage. Geomechanics for Energy and the Environment $11,28-41$.

Lipponen, J., McCulloch, S., Keeling, S., Stanley, T., Berghout, N., Berly, T., 2017. The Politics of large-scale CCS Deployment. Energy Procedia 114, 7581 - 7595, 13th International Conference on Greenhouse Gas Control Technologies, GHGT-13, 14-18 November 2016, Lausanne, Switzerland.

Lofstedt, R., 2015. Effective risk communication and ccs: the road to success in europe. Journal of Risk Research 18 (6), 675-691.

Louis, L., Baud, P., Wong, T., 2017. A new model for failure and yield envelopes of anisotropic porous sandstone. In: 51st US Rock Mechanics/Geomechanics Symposium. American Rock Mechanics Association.

Lyu, Q., Long, X., Ranjith, P., Tan, J., Kang, Y., 2018. Experimental investigation on the mechanical behaviours of a low-clay shale under waterbased fluids. Engineering Geology 233, $124-138$.

Mabon, L., Shackley, S., Blackford, J., Stahl, H., Miller, A., 2015. Local perceptions of the QICS experimental offshore CO2 release: results from social science research. International Journal of Greenhouse Gas Control 38, 18-25.

Mabon, L., Shackley, S., Bower-Bir, N., 2014. Perceptions of sub-seabed carbon dioxide storage in scotland and implications for policy: A qualitative study. Marine Policy 45, $9-15$.

Mabon, L., Vercelli, S., Shackley, S., Anderlucci, J., Battisti, N., e. a., 2013. Tell me what you think about the geological storage of carbon dioxide: towards a fuller understanding of public perceptions of ccs. Energy Procedia 37.

MacNeil, A., Ali, R., Blenkinsop, T., Carmichael, A., Davies, G., Heappey, J., Pennycook, M., Poulter, D., Reed, J., Sandbach, A., Sturdy, J., 2016. Future of carbon capture and storage in the UK, Second Report of Session 2015-16. Tech. rep., House of Commons London: The Stationery Office Limited.

Maldal, T., Tappel, I., 2003. $\mathrm{CO}_{2}$ Underground Storage for Snøhvit Gas Field Development. In: Gale, J., Kaya, Y. (Eds.), Greenhouse Gas Control Technologies - 6th International Conference. Pergamon, Oxford, pp. $601-606$.

Marbler, H., Erickson, K. P., Schmidt, M., Lempp, C., Pöllmann, H., Jul 2013. Geomechanical and geochemical effects on sandstones caused by the reaction with supercritical co2: an experimental approach to in situ conditions in deep geological reservoirs. Environmental Earth Sciences 69 (6), 1981-1998.

Markewitz, P., Kuckshinrichs, W., Leitner, W., Linssen, J., Zapp, P., Bongartz, R., Schreiber, A., Müller, T. E., 2012. Worldwide innovations in the development of carbon capture technologies and the utilization of $\mathrm{CO}_{2}$. Energy Environ. Sci. 5, 7281-7305.

Marshall, J. D., Tucker, O. D., Lovelock, C. E., Darker, S. J., Annia, C. E., Hognestad, J. B., 2017. Goldeneye: Tomorrow Never Dies (or a field Only Lives Twice). Geological Society, London, Petroleum Geology Conference series 8.

Mathieson, A., Midgely, J., Wright, I., Saoula, N., Ringrose, P., 2011. In Salah $\mathrm{CO}_{2}$ Storage JIP: CO 2 sequestration monitoring and verification technologies applied at Krechba, Algeria. Energy Procedia 4, 3596 - 3603, 10th International Conference on Greenhouse Gas Control Technologies.

IPCC Special Report on Carbon Dioxide Capture and Storage, 2005. Intergovernmental Panel on Climate Change.

McDermott, C., Williams, J., Tucker, O., Jin, M., Mackay, E., Edlmann, K., Haszeldine, R. S., Wang, W., Kolditz, O., Akhurst, M., 2016. Screening the geomechanical stability (thermal and mechanical) of shared multi-user $\mathrm{CO}_{2}$ storage assets: A simple effective tool applied to the Captain Sandstone Aquifer. International Journal of Greenhouse Gas Control 45 (Supplement C), 43-61.

Mehin, K., Constantine, A. E., 1999. Hydrocarbon potential of the Western onshore Otway Basin in Victoria. Department of Natural Resources and Environment.

Midden, C. J. H., Huijts, N. M. A., 2009. The role of trust in the affective evaluation of novel risks: The case of co 2 storage. Risk Analysis 29 (5), $743-751$.

Miersemann, U., Loizzo, M., Lamy, P., 2010. Evaluating old wells for conversion to $\mathrm{co}_{2}$ injectors: Experience from the rousse field. Society of Petroleum Engineers Journal SPE-139506-MS, https://doi.org/10.2118/139506-MS.

Mitchell, J. K., Green, R. A., 2017. Some induced seismicity considerations in geo-energy resource development. Geomechanics for Energy and the Environment 10, 3 - 11, geo-Energy and Geo-Environment.

Morris, J. P., Hao, Y., Foxall, W., McNab, W., 2011. In Salah $\mathrm{CO}_{2}$ storage JIP: hydromechanical simulations of surface uplift due to CO 2 injection at In Salah. Energy Procedia 4 (Supplement C), 3269-3275.

Mortazavi, A., Atapour, H., 2018. An experimental study of stress changes induced by reservoir depletion under true triaxial stress loading conditions. Journal of Petroleum Science and Engineering 171, 1366 - 1377.

MUSTANG, 2014a. MUSTANG Report D073: Results of site models. Tech. rep., European Commission.

MUSTANG, 2014b. MUSTANG Report D076: Synthesis of modelling results. Tech. rep., Seventh Framework Programme, European Commission.

Mutschler, T., Triantafyllidis, T., Balthasar, K., 2009. Geotechnical investigations of cap rocks above co2 -resevoirs. Energy Procedia 1 (1), $3375-$ 3382.

Myshakin, E. M., Singh, H., Sanguinito, S., Bromhal, G., Goodman, A. L., 2018. Numerical estimations of storage efficiency for the prospective 
$\mathrm{CO}_{2}$ storage resource of shales. International Journal of Greenhouse Gas Control 76, $24-31$.

Neuzil, C. E., 1994. How permeable are clays and shales? Water Resources Research 30(2), 145-150.

Nguyen, V., Gland, N., Dautriat, J., David, C., Wassermann, J., Guélard, J., 2014. Compaction, permeability evolution and stress path effects in unconsolidated sand and weakly consolidated sandstone. International Journal of Rock Mechanics and Mining Sciences 67, 226 - 239.

Nicksiar, M., Martin, C. D., Jul 2012. Evaluation of methods for determining crack initiation in compression tests on low-porosity rocks. Rock Mechanics and Rock Engineering 45 (4), 607-617.

Niemi, A., Bensabat, J., Shtivelman, V., Edlmann, K., Gouze, P., Luquot, L., Hingerl, F., Benson, S., Pezard, P., Rasmusson, K., Liang, T., Fagerlund, F., Gendler, M., Goldberg, I., Tatomir, A., Lange, T., Sauter, M., Freifeld, B., 5 2016. Heletz experimental site overview, characterization and data analysis for $\mathrm{CO}_{2}$ injection and geological storage. International Journal of Greenhouse Gas Control 48, 3-23.

Norden, B., Förster, A., Vu-Hoang, D., Marcelis, F., Springer, N., Le Nir, I., 2008. Lithological and petrophysical core-log interpretation in the $\mathrm{CO}_{2}$ SINK, the European $\mathrm{CO}_{2}$ onshore research storage and verification project. In: SPE Asia Pacific Oil and Gas Conference and Exhibition (APOGCE) (Perth, Australia 2008).

Norden, B., Frykman, P., 2013. Geological modelling of the triassic stuttgart formation at the ketzin $\mathrm{co}_{2}$ storage site, germany. International Journal of Greenhouse Gas Control 19, 756 - 774.

Olden, P., Pickup, G., Jin, M., Mackay, E., Hamilton, S., Somerville, J., Todd, A., 2012. Use of rock mechanics laboratory data in geomechanical modelling to increase confidence in $\mathrm{co}_{2}$ geological storage. International Journal of Greenhouse Gas Control 11, $304-315$.

Oldenburg, C. M., Jordan, P. D., Nicot, J.-P., Mazzoldi, A., Gupta, A. K., Bryant, S. L., 2011. Leakage risk assessment of the In Salah CO 2 storage project: Applying the certification framework in a dynamic context. Energy Procedia 4 (Supplement C), 4154-4161.

Oltra, C., Sala, R., Solà, R., Masso, M. D., Rowe, G., 2010. Lay perceptions of carbon capture and storage technology. International Journal of Greenhouse Gas Control 4 (4), 698 - 706.

Oltra, C., Upham, P., Riesch, H., Boso, A., Brunsting, S., Dütschke, E., Lis, A., 2012. Public responses to $\mathrm{co}_{2}$ storage sites: Lessons from five european cases. Energy \& Environment 23 (2-3), 227-248.

Orlic, B., 2016. Geomechanical effects of $\mathrm{CO}_{2}$ storage in depleted gas reservoirs in the Netherlands: Inferences from feasibility studies and comparison with aquifer storage. Journal of Rock Mechanics and Geotechnical Engineering 8(6), 846-859.

Orlic, B., ter Heege, J., Wassing, B., 2011a. Assessing the integrity of fault- and top seals at $\mathrm{CO}_{2}$ storage sites. Energy Procedia 4 (Supplement C), 4798-4805.

Orlic, B., Ter Heege, J., Wassing, B. B. T., Others, 2011b. Assessing the short-term and long-term integrity of top seals in feasibility studies of geological $\mathrm{CO}_{2}$ storage. In: 45th US Rock Mechanics/Geomechanics Symposium. American Rock Mechanics Association, San Francisco, CA.

Ouellet, A., Bérard, T., Desroches, J., Frykman, P., Welsh, P., Minton, J., Pamukcu, Y., Hurter, S., Schmidt-Hattenberger, C., 2011. Reservoir geomechanics for assessing containment in $\mathrm{Co}_{2}$ storage: A case study at ketzin, germany. Energy Procedia 4, 3298 - 3305, 10th International Conference on Greenhouse Gas Control Technologies.

Paluszny, A., Matthäi, S. K., 2010. Impact of fracture development on the effective permeability of porous rocks as determined by 2D discrete fracture growth modeling. Journal of Geophysical Research: Solid Earth 115 (B2).

Paluszny, A., Salimzadeh, S., Tempone, P., Zimmerman, R. W., 2017. Evaluating Natural Fracture Growth in Shale Caprocks During Cold CO Injection at the Heletz Pilot Site. In: 51st US Rock Mechanics / Geomechanics Symposium. American Rock Mechanics Association, San Francisco, CA.

Pan, P.-Z., Rutqvist, J., Feng, X.-T., Yan, F., Mar 2014. An Approach for Modeling Rock Discontinuous Mechanical Behavior Under Multiphase Fluid Flow Conditions. Rock Mechanics and Rock Engineering 47 (2), 589-603.

URL https : //doi .org/10.1007/s00603-013-0428-1

Paterson, L., Boreham, C., Bunch, M., Dance, T., Ennis-King, J., Freifeld, B., Haese, R., Jenkins, C., LaForce, T., Raab, M., Singh, R., Stalker, L., Zhang, Y., 2013. Overview of the $\mathrm{co}_{2} \mathrm{crc}$ otway residual saturation and dissolution test. Energy Procedia 37, 6140 - 6148, gHGT-11 Proceedings of the 11th International Conference on Greenhouse Gas Control Technologies, 18-22 November 2012, Kyoto, Japan.

Peters, E., Pizzocolo, F., Loeve, D., Fokker, P. A., Hofstee, C., Orlic, B., Maas, J. G., 2013. Consequences of thermal fracture developments due to injection cold $\mathrm{CO}_{2}$ into depleted gas fields. Energy Procedia, 1-18.

Pham, T. H. V., Maast, T. E., Hellevang, H., Aagaard, P., 2011. Numerical modeling including hysteresis properties for $\mathrm{CO}_{2}$ storage in Tubåen formation, Snøhvit field, Barents Sea. Energy Procedia 4 (Supplement C), 3746-3753.

Pires, J., Martins, F., Alvim-Ferraz, M., Simões, M., 2011. Recent developments on carbon capture and storage: An overview. Chemical Engineering Research and Design 89 (9), 1446 - 1460, special Issue on Carbon Capture \& Storage.

Potts, D. M., Zdravković, L., 1999. Finite element analysis in geotechnical engineering: theory. Thomas Telford, London.

Poumadère, M., Bertoldo, R., Samadi, J., 2011. Public perceptions and governance of controversial technologies to tackle climate change: nuclear power, carbon capture and storage, wind, and geoengineering. Wiley Interdisciplinary Reviews: Climate Change 2 (5), $712-727$.

Pourtoy, D., Onaisi, A., Lescanne, M., Thibeau, S., Viaud, C., 2013. Seal Integrity of the Rousse Depleted Gas Field Impacted by CO 2 Injection (Lacq Industrial CCS Reference Project France). Energy Procedia 37 (Supplement C), 5480-5493.

Preisig, M., Prévost, J. H., 2011. Coupled multi-phase thermo-poromechanical effects. Case study: $\mathrm{CO}_{2}$ injection at In Salah, Algeria. International Journal of Greenhouse Gas Control 5 (4), 1055-1064.

Prinet, C., Thibeau, S., Lescanne, M., Monne, J., 2013. Lacq-Rousse $\mathrm{CO}_{2}$ Capture and Storage demonstration pilot: Lessons learnt from two and a half years monitoring. Energy Procedia 37, 3610-3620.

Rai, V., Chung, N.-C., Thurber, M. C., Victor, D. G., 2008. Energy Efficiency and CO2 emission reductions in the Iron and Steel Industry. Tech. rep., Stanford University, program on Energy and Sustainable Development Working Paper Nr. 76.

Rastelli, E., Corinaldesi, C., Dell'Anno, A., Amaro, T., Greco, S., Martire, M. L., Carugati, L., Queirós, A. M., Widdicombe, S., Danovaro, R., 2016. $\mathrm{CO}_{2}$ leakage from carbon dioxide capture and storage (CCS) systems affects organic matter cycling in surface marine sediments. Marine Environmental Research 122, 158 - 168.

Rathnaweera, T., Ranjith, P., Perera, M., Wanniarachchi, W., Bandara, K., 2018. Stress state and stress path evaluation to address uncertainties in reservoir rock failure in $\mathrm{CO}_{2}$ sequestration in deep saline aquifers: An experimental study of the hawkesbury sandstone formation. Journal of CO2 Utilization 26, $184-201$. 
RCUK, 2010. Progressing UK energy research for a coherent structure with impact. Tech. rep., International Panel for the RCUK Review of Energy 2010. RCUK, Swindon.

Read, A., Tillema, O., Ros, M., Jonker, T., Hylkema, H., 2014. Update on the road project and lessons learnt. Energy Procedia 63, 6079 - 6095, 12th International Conference on Greenhouse Gas Control Technologies, GHGT-12.

Reuters, 2011. Vattenfall drops carbon capture project in Germany.

URL https://www.reuters.com/article/vattenfall-carbon/update-2-vattenfall-drops-carbon-capture-project-in-germany-idUSL5E7

Rinaldi, A. P., Rutqvist, J., 2017. Modeling Ground Surface Uplift During $\mathrm{CO}_{2}$ Sequestration: The Case of in Salah, Algeria. Energy Procedia 114 (Supplement C), 3247-3256.

Ringrose, P., Mathieson, A., Wright, I., Selama, F., Hansen, O., Bissell, R., Saoula, N., Midgley, J., 2013. The In Salah CO 2 Storage Project: Lessons Learned and Knowledge Transfer. Energy Procedia 37, 6226 - 6236, gHGT-11 Proceedings of the 11th International Conference on Greenhouse Gas Control Technologies, 18-22 November 2012, Kyoto, Japan.

Roberts, J. J., Wilkinson, M., Naylor, M., Shipton, Z. K., Wood, R. A., Haszeldine, R. S., 2017. Natural CO 2 sites in Italy show the importance of overburden geopressure, fractures and faults for $\mathrm{CO}_{2}$ storage performance and risk management. Geological Society, London, Special Publications 458.

Roberts, T., Mander, S., 2011. Assessing public perceptions of ccs: Benefits, challenges and methods. Energy Procedia 4, 6307 - 6314, 10th International Conference on Greenhouse Gas Control Technologies.

Rockström, J., Gaffney, O., Rogelj, J., Meinshausen, M., Nakicenovic, N., Schellnhuber, H. J., 2017. A roadmap for rapid decarbonization. Science 355 (6331), 1269-1271.

Rodríguez-Romero, A., Jiménez-Tenorio, N., Riba, I., Blasco, J., 2016. Laboratory simulation system, using Carcinus maenas as the model organism, for assessing the impact of $\mathrm{CO}_{2}$ leakage from sub-seabed injection and storage. Environmental Research 144,117 - 129.

Rutqvist, J., 2011. Status of the tough-flac simulator and recent applications related to coupled fluid flow and crustal deformations. Computers \& Geosciences 37 (6), 739 - 750, 2009 Transport of Unsaturated Groundwater and Heat Symposium.

Rutqvist, J., jun 2012. The Geomechanics of $\mathrm{CO}_{2}$ Storage in Deep Sedimentary Formations. Geotechnical and Geological Engineering 30 (3), 525-551.

Rutqvist, J., Vasco, D. W., Myer, L., 2010. Coupled reservoir-geomechanical analysis of $\mathrm{co}_{2}$ injection and ground deformations at in salah, algeria. International Journal of Greenhouse Gas Control 4 (2), 225 - 230, the Ninth International Conference on Greenhouse Gas Control Technologies.

Rybacki, E., Reinicke, A., Meier, T., Makasi, M., Dresen, G., 2015. What controls the mechanical properties of shale rocks? - part i: Strength and young's modulus. Journal of Petroleum Science and Engineering 135, $702-722$.

Sacuta, N., Daly, D., Botnen, B., Worth, K., 2017. Communicating about the Geological Storage of Carbon Dioxide - Comparing Public Outreach for $\mathrm{CO}_{2}$ EOR and Saline Storage Projects. Energy Procedia 114, 7245 - 7259.

Saeedi, A., Rezaee, R., 2012. Effect of residual natural gas saturation on multiphase flow behaviour during $\mathrm{CO}_{2}$ geo-sequestration in depleted natural gas reservoirs. Journal of Petroleum Science and Engineering 82-83, 17 - 26

Saeedi, A., Rezaee, R., Evans, B., Clennell, B., 2011. Multiphase flow behaviour during $\mathrm{CO}_{2}$ geo-sequestration: Emphasis on the effect of cyclic $\mathrm{CO}_{2}$-brine flooding. Journal of Petroleum Science and Engineering 79 (3), 65 - 85.

Salimzadeh, S., Paluszny, A., Nick, H. M., Zimmerman, R. W., 2018b. A three-dimensional coupled thermo-hydro-mechanical model for deformable fractured geothermal systems. Geothermics 71, $212-224$.

Salimzadeh, S., Paluszny, A., Zimmerman, R. W., 2018a. Effect of cold $\mathrm{CO}_{2}$ injection on fracture apertures and growth. International Journal of Greenhouse Gas Control 74, 130 - 141.

Salimzadeh, S., Usui, T., Paluszny, A., Zimmerman, R. W., 2017. Finite element simulations of interactions between multiple hydraulic fractures in a poroelastic rock. International Journal of Rock Mechanics and Mining Sciences 99, 9- 20.

Sander, R., Pan, Z., Connell, L. D., 2017. Laboratory measurement of low permeability unconventional gas reservoir rocks: A review of experimental methods. Journal of Natural Gas Science and Engineering 37, $248-279$.

Sara, J., Stikkelman, R. M., Herder, P. M., 2015. Assessing relative importance and mutual influence of barriers for CCS deployment of the ROAD project using AHP and DEMATEL methods. International Journal of Greenhouse Gas Control 41, 336 - 357.

Schumann, D., Duetschke, E., Pietzner, K., 2014. Public perception of $\mathrm{co}_{2}$ offshore storage in germany: Regional differences and determinants. Energy Procedia 63, 7096 - 7112, 12th International Conference on Greenhouse Gas Control Technologies, GHGT-12.

Schutjens, P., Hanssen, T., Hettema, M., Merour, J., Bree, P. D., Coremans, J., Helliesen, G., 2004. Compaction-induced porosity/permeability reduction in sandstone reservoirs: Data and model for elasticity-dominated deformation. In: SPE Reservoir Evaluation \& Engineering. Vol. 7. pp. 202-216.

Seigo, S. L., Arvai, J., Dohle, S., Siegrist, M., 2014a. Predictors of risk and benefit perception of carbon capture and storage (ccs) in regions with different stages of deployment. International Journal of Greenhouse Gas Control 25, 23 - 32.

Seigo, S. L., Dohle, S., Siegrist, M., 2014b. Public perception of carbon capture and storage (ccs): A review. Renewable and Sustainable Energy Reviews 38, $848-863$.

Selvadurai, A. P. S., Suvorov, A. P., Selvadurai, P. A., 2015. Thermo-hydro-mechanical processes in fractured rock formations during a glacial advance. Geoscientific Model Development 8 (7), 2167-2185.

SETIS, 2019. Energy Efficiency and CO2 emission reductions in the Iron and Steel Industry. Tech. rep., European Commission. Strategic energy technologies information system.

Shackley, S., McLachlan, C., Gough, C., 2004. The public perception of carbon dioxide capture and storage in the uk: results from focus groups and a survey. Climate Policy 4 (4), 377-398.

Shackley, S., Waterman, H., Godfroij, P., Reiner, D., Anderson, J., Draxlbauer, K., Flach, T., 2007. Stakeholder perceptions of co 2 capture and storage in europe: Results from a survey. Energy Policy 35 (10), $5091-5108$

Sharp, D., Jaccard, M., Keith, D., 2009. Anticipating public attitudes toward underground CO2 storage. International Journal of Greenhouse Gas Control 3 (5), 641-651.

Sheldon, H., Barnicoat, A., Ord, A., 2006. Numerical modelling of faulting and fluid flow in porous rocks: An approach based on critical state soil mechanics. Journal of Structural Geology 28 (8), $1468-1482$. 
Shell, 2008. Summary environmental impact assessment: underground storage of $\mathrm{CO}_{2}$ in Barendrecht. Tech. rep.

Shell, 2011. UK Carbon Capture and Storage Demonstration Competition. Tech. rep., Shell.

Shi, J.-Q., Smith, J., Durucan, S., Korre, A., 2013. A Coupled Reservoir Simulation-geomechanical Modelling Study of the CO 2 Injection-induced Ground Surface Uplift Observed at Krechba, In Salah. Energy Procedia 37 (Supplement C), 3719-3726.

Shipton, Z. K., Evans, J. P., Kirschner, D., Kolesar, P. T., Williams, A. P., Heath, J., 2004. Analysis of $\mathrm{CO}_{2}$ leakage through 'low-permeability' faults from natural reservoirs in the Colorado Plateau, east-central Utah. Geological Society, London, Special Publications 233 (1), $43-58$.

Siggins, A. F., 2006. Velocity-effective stress response of $\mathrm{co}_{2}$-saturated sandstones. Exploration Geophysics 37, 60-66.

Slovic, P., Layman, M., Flynn, J., 1991. Perceived risk, trust, and nuclear waste: lessons from Yucca mountain. Duke University Press.

Sone, H., Zoback, M. D., 2013a. Mechanical properties of shale-gas reservoir rocks — Part 1: Static and dynamic elastic properties and anisotropy. Geophysics 78 (5), D381-D392.

Sone, H., Zoback, M. D., 2013b. Mechanical properties of shale-gas reservoir rocks - Part 2: Ductile creep, brittle strength, and their relation to the elastic modulusMechanical properties of gas shale — Part 2. Geophysics 78 (5), D393.

Spence, B., Horan, D., Tucker, O., 2014. The peterhead-goldeneye gas post-combustion CCS project. Energy Procedia 63, 6258 - 6266, 12 th International Conference on Greenhouse Gas Control Technologies, GHGT-12.

Stark, C., Thompson, M., 2019. Net Zero: The UK's contribution to stopping global warming. Tech. rep., Committee on Climate Change.

Steeper, T., 2013. $\mathrm{Co}_{2}$ crc otway project social research: Assessing CCS community consultation. Energy Procedia 37, 7454 - 7461, gHGT-11 Proceedings of the 11th International Conference on Greenhouse Gas Control Technologies, 18-22 November 2012, Kyoto, Japan.

Strömberg, L., Lindgren, G., Jacoby, J., Giering, R., Anheden, M., Burchhardt, U., Altmann, H., Kluger, F., Stamatelopoulos, G.-N., 2009. Update on vattenfall's 30 mwth oxyfuel pilot plant in Schwarze Pumpe. Energy Procedia 1 (1), 581 - 589, greenhouse Gas Control Technologies 9.

Sullivan, M. D., Haszeldine, R. S., Fallick, A. E., 1990. Linear coupling of carbon and strontium isotopes in rotliegend sandstone, north sea: Evidence for cross-formational fluid flow. Geology 18, 1215-1218.

Tanikawa, W., Shimamoto, T., 2009. Comparison of klinkenberg-corrected gas permeability and water permeability in sedimentary rocks. International Journal of Rock Mechanics and Mining Sciences 46, 229-238.

Tapia, J. F. D., Lee, J.-Y., Ooi, R. E., Foo, D. C., Tan, R. R., 2018. A review of optimization and decision-making models for the planning of CO 2 capture, utilization and storage (CCUS) systems. Sustainable Production and Consumption 13, $1-15$.

Teesside Collective UK, 2015. Blueprint for industrial CCS in the UK: Executive summary. Tech. rep., Teesside Collective UK.

Teir, S., Tsupari, E., Arasto, A., Koljonen, T., Kärki, J., Lehtilä, A., Kujanpää, L., Aatos, S., Nieminen, M., 2011. Prospects for application of CCS in Finland. Energy Procedia 4, 6174 - 6181, 10th International Conference on Greenhouse Gas Control Technologies.

Tenthorey, E., Dance, T., Cinar, Y., Ennis-King, J., Strand, J., 2014. Fault modelling and geomechanical integrity associated with the co 2 crc otway 2c injection experiment. International Journal of Greenhouse Gas Control 30, $72-85$.

Terwel, B. W., Harinck, F., Ellemers, N., Daamen, D. D., 2011. Going beyond the properties of con capture and storage (ccs) technology: How trust in stakeholders affects public acceptance of ccs. International Journal of Greenhouse Gas Control 5 (2), $181-188$.

Terwel, B. W., ter Mors, E., Daamen, D. D., 2012. It's not only about safety: Beliefs and attitudes of 811 local residents regarding a CCS project in barendrecht. International Journal of Greenhouse Gas Control 9, $41-51$.

Thibeau, S., Chiquet, P., Prinet, C., Lescanne, M., 2013. Lacq-Rousse $\mathrm{CO}_{2}$ Capture and Storage Demonstration Pilot: Lessons Learnt from Reservoir Modelling Studies. Energy Procedia 37, 6306 - 6316, gHGT-11 Proceedings of the 11th International Conference on Greenhouse Gas Control Technologies, 18-22 November 2012, Kyoto, Japan.

Thomas, R. N., 2019. Permeability of fracture networks generated through geomechanical fracture-growth simulations. Ph.D. thesis, Imperial College London.

Thomas, R. N., Paluszny, A., Zimmerman, R. W., 2017. Quantification of fracture interaction using stress intensity factor variation maps. Journal of Geophysical Research: Solid Earth 122 (10), 7698-7717.

Tonnet, N., Mouronval, G., Chiquet, P., Broseta, D., 2011. Petrophysical assessment of a carbonate-rich caprock for $\mathrm{CO}_{2}$ geological storage purposes. Energy Procedia 4, 5422 - 5429, 10th International Conference on Greenhouse Gas Control Technologies.

Total, 2015. Carbon capture and storage: the Lacq pilot. Project and injection period 2006-2013. Tech. rep., Total.

Turley, C., Blackford, J. C., Widdicombe, S., Lowe, D., Nightingale, P. D., Rees, A. P., 2006. Reviewing the impact of increased atmospheric co 2 on oceanic ph and the marine ecosystem. In: Schellnhuber, H. J., Cramer, W., Nakicenovic, N., Wigley, T., Yohe, G. (Eds.), Avoiding Dangerous Climate Change. Cambridge University Press, pp. 65-70.

Upham, P., Roberts, T., 2011a. Public perceptions of ccs: Emergent themes in pan-european focus groups and implications for communications. International Journal of Greenhouse Gas Control 5 (5), 1359 - 1367.

Upham, P., Roberts, T., 2011b. Public perceptions of CCS in context: Results of nearco 2 focus groups in the uk, belgium, the netherlands, germany, spain and poland. Energy Procedia 4, 6338 - 6344, 10th International Conference on Greenhouse Gas Control Technologies.

van Alphen, K., van Voorst tot Voorst, Q., Hekkert, M. P., Smits, R. E., 2007. Societal acceptance of carbon capture and storage technologies. Energy Policy 35 (8), $4368-4380$.

van Dijk, H., Damen, K., Makkee, M., Trapp, C., 2014. Water-gas shift (WGS) Operation of Pre-combustion CO ${ }_{2}$ Capture Pilot Plant at the Buggenum IGCC. Energy Procedia 63, 2008 - 2015, 12th International Conference on Greenhouse Gas Control Technologies, GHGT-12.

van Eijs, R., Kuijper, M., Bisschop, R., 2011. Containment demonstration for the Barendrecht $\mathrm{CO}_{2}$ storage project. Energy Procedia 4 (Supplement C), 4092-4099.

van Knippenberg, D., Daamen, D., 1996. Providing information in public opinion surveys: motivation and ability effects in the information-andchoice questionnaire. International Journal of Public Opinion Research 8 (1), 70-82.

Vandepaer, L., Cloutier, J., Amor, B., 2017. Environmental impacts of Lithium Metal Polymer and Lithium-ion stationary batteries. Renewable and Sustainable Energy Reviews 78, 46 - 60.

Vandeweijer, V., Groenenberg, R., Donselaar, M. E. D., Pluymaekers, M., Loeve, D., Hofstee, C., Nepveu, M. D., Orlic, B., Arts, R., Neele, F., Meindertsma, W., 2011. Feasibility study P18 (final report). Tech. Rep. CATO2-WP3.01-D06, CATO.

Vasco, D. W., Rucci, A., Ferretti, A., Novali, F., Bissell, R. C., Ringrose, P. S., Mathieson, A. S., Wright, I. W., 2010. Satellite-based measurements of surface deformation reveal fluid flow associated with the geological storage of carbon dioxide. Geophysical Research Letters 37 (3). 
Vercelli, S., Anderlucci, J., Memoli, R., Battisti, N., Mabon, L., Lombardi, S., 2013. Informing people about ccs: A review of social research studies. Energy Procedia 37, 7464 - 7473, gHGT-11 Proceedings of the 11th International Conference on Greenhouse Gas Control Technologies, 18-22 November 2012, Kyoto, Japan.

Vercelli, S., Lombardi, S., Bigi, S., Tartarello, M. C., Finoia, M. G., Dolcetti, F., 2017. Topic and Concerns Related to the Potential Impacts of $\mathrm{CO}_{2}$ Storage: Results from a Stakeholders Questionnaire. Energy Procedia 114, 7379 - 7398, 13th International Conference on Greenhouse Gas Control Technologies, GHGT-13, 14-18 November 2016, Lausanne, Switzerland.

Verdon, J. P., Stork, A. L., Bissell, R. C., Bond, C. E., Werner, M. J., 2015. Simulation of seismic events induced by co 2 injection at in salah, algeria. Earth and Planetary Science Letters 426, 118 - 129.

Vidal, O., Goffe, B., Arndt, N., 2013. Metals for a low-carbon society. Nature Geoscience 6, 894-896.

Vidal-Gilbert, S., Tenthorey, E., Dewhurst, D., Ennis-King, J., Ruth, P. V., Hillis, R., 2010. Geomechanical analysis of the naylor field, otway basin, australia: Implications for $\mathrm{CO}_{2}$ injection and storage. International Journal of Greenhouse Gas Control 4 (5), 827 - 839.

Vilarrasa, V., Laloui, L., jul 2015. Potential fracture propagation into the caprock induced by cold $\mathrm{CO}_{2}$ injection in normal faulting stress regimes. Geomechanics for Energy and the Environment 2, 22-31.

Vilarrasa, V., Rutqvist, J., Rinaldi, A. P., aug 2015. Thermal and capillary effects on the caprock mechanical stability at In Salah, Algeria. Greenhouse Gases: Science and Technology 5 (4), 449-461.

Vilarrasa, V., Silva, O., Carrera, J., Olivella, S., may 2013. Liquid $\mathrm{CO}_{2}$ injection for geological storage in deep saline aquifers. International Journal of Greenhouse Gas Control 14, 84-96.

Wallquist, L., Seigo, S. L., Visschers, V. H., Siegrist, M., 2012. Public acceptance of CCS system elements: A conjoint measurement. International Journal of Greenhouse Gas Control 6, $77-83$.

Wallquist, L., Visschers, V. H. M., Dohle, S., Siegrist, M., 2011. Adapting communication to the public's intuitive understanding of ccs. Greenhouse Gases: Science and Technology 1 (1), 83-91.

Wallquist, L., Visschers, V. H. M., Siegrist, M., 2010. Impact of knowledge and misconceptions on benefit and risk perception of CCS. Environmental Science \& Technology 44 17, 6557-62.

Wang, H. F., 2000. Theory of linear poroelasticity: with applications to geomechanics and hydrogeology. Ph.D. thesis, Princeton University.

Warren, D. C., Carley, S. R., Krause, R. M., Rupp, J. A., Graham, J. D., 2014. Predictors of attitudes toward carbon capture and storage using data on world views and ccs-specific attitudes. Science and Public Policy 41 (6), 821-834.

Watson, M., Cinar, Y., Dance, T., Pevzner, R., Tenthorey, E., Caspari, E., Ennis-King, J., Shulakova, V., Bunch, M., Urosevic, M., Others, 2012. Otway stage $2 \mathrm{C}$ science report-Verification of $\mathrm{CO}_{2}$ storage in a saline formation (Paaratte) using time lapse seismic. $\mathrm{CO}_{2} \mathrm{CRC}$ Publication $\mathrm{No}$. RPT12-4109, 220

Wennberg, O. P., Malm, O., Needham, T., Edwards, E., Ottesen, S., Karlsen, F., Rennan, L., Knipe, R., 2008. On the occurrence and formation of open fractures in the Jurassic reservoir sandstones of the Snøhvit Field, SW Barents Sea. Petroleum Geoscience 14 (2), 139-150.

Wennersten, R., Sun, Q., Li, H., 2015. The future potential for carbon capture and storage in climate change mitigation - an overview from perspectives of technology, economy and risk. Journal of Cleaner Production 103, 724 - 736, carbon Emissions Reduction: Policies, Technologies, Monitoring, Assessment and Modeling.

White, J. A., Chiaramonte, L., Ezzedine, S., Foxall, W., Hao, Y., Ramirez, A., McNab, W., jun 2014. Geomechanical behavior of the reservoir and caprock system at the In Salah $\mathrm{CO}_{2}$ storage project. Proceedings of the National Academy of Sciences of the United States of America 111 (24), 8747-52.

Whitmarsh, L., Xenias, D., Jones, C., 2019. Framing effects on public support for carbon capture and storage. Palgrave Communications 5 (17).

Wilkinson, I. P., 2006. The holostratigraphy of the Albian Stage (Lower Cretaceous) of the United Kingdom and its continental shelf. Tech. rep., British Geological Survey.

Wright, I. W., 2007. The in salah gas $\mathrm{co}_{2}$ storage project. In: IPTC 2007: International Petroleum Technology Conference.

Xenias, D., Whitmarsh, L., 2018. Carbon capture and storage (CCS) experts' attitudes to and experience with public engagement. International Journal of Greenhouse Gas Control 78, 103 - 116.

Xiong, Y., Fakcharoenphol, P., Hu, L., Winterfeld, P. H., Xu, T., Wu, Y.-S., 2013. TOUGH2-EGS: A Coupled Geomechanical and Reactive Geochemical Simulator for Fluid and Heat Flow in Enhanced Geothermal Systems. Version 1.0. Tech. rep., Colorado School of Mines.

Yaliz, A., Taylor, P., 2003. The hamilton and hamilton north gas fields, block 110/13a, east irish sea. Geological Society, London, Memoirs 20 (1), 77-86.

Yaliz, A. M., 1997. The douglas oil field in, petroleum geology of the irish sea and adjacent areas. n. s. meadows, s. p. trueblood, m. hardman and g. cowan (eds.). Geological Society Special Publication 124, 399-416.

Yang, L., Zhang, X., McAlinden, K. J., 2016. The effect of trust on people's acceptance of CCS (carbon capture and storage) technologies: Evidence from a survey in the people's republic of china. Energy 96, $69-79$.

Zapantis, A., Townsend, A., Rassool, D., 2019. Policy priorities to incentivise large scale deployment of CCS. Tech. rep., Global CCS Institute.

Zareidarmiyan, A., Salarirad, H., Vilarrasa, V., De Simone, S., Olivella, S., 2018. Geomechanical response of fractured reservoirs. Fluids 3 (4).

Zero Emission Resource Organisation, 2016. Ccs database. http://www.zeroCO 2 .no/projects/meri-pori.

Zimmerman, R. W., 2000. Coupling in poroelasticity and thermoelasticity. International Journal of Rock Mechanics and Mining Sciences 37 (1-2), 79-87. 